\title{
EL TRATAMIENTO JURÍDICO-PENAL BRASILEÑO DE LA GORRUPGIÓN PRIVADA A PARTIR DE UN ANÁLISIS DE DERECHO GOMPARADO*
}

\author{
THE BRAZILIAN LEGAL-CRIMINAL TREATMENT OF PRIVATE \\ CORRUPTION FROM A COMPARATIVE LAW ANALYSIS
}

\section{Carlos Eduardo GOnÇALves DE GODOI**}

RESUMEN: Si bien en América Latina existen diversos estudios sobre la responsabilidad de servidores públicos en los ámbitos tanto penal como administrativo, así como de los particulares con ellos vinculados, el tema de las responsabilidades por actos de corrupción entre particulares ha sido mucho menos estudiado, y este contexto llega al marco legislativo, ya que la tipificación del cohecho está ampliamente consolidada en las legislaciones nacionales, mientras que la tipificación penal de los particulares que implican corrupción aún alcanza pocos ordenamientos jurídicos como el de Brasil. Este estudio tiene como objetivo demostrar la relevancia del tratamiento penal de la corrupción en el sector privado y resaltar las distancias entre el marco regulatorio brasileño y el de otros países, incluso dentro de una perspectiva regional, para estimular el debate sobre el tema y las posibles soluciones a la falta de regulación.

Palabras clave: Brasil, corrupción, sector privado, tipificación penal.
ABSTRACT: Although in Latin America there are various studies on the responsibility of public servants in both criminal and administrative spheres, as well as individuals linked to them, the issue of responsibilities for acts of corruption between individuals has been much less studied, and this The context reaches the legislative framework, since the classification of bribery is widely consolidated in national legislation, while the criminal classification of individuals who involve corruption still reaches few legal systems such as that of Brazil. This study aims to demonstrate the relevance of the criminal treatment of corruption in the private sector and highlight the distances between the Brazilian regulatory framework and that of other countries, even within a regional perspective, to stimulate debate on the subject and the possible solutions to the lack of regulation.

Keyzerds: Brazil, corruption, private sector, criminal classification.

* Recibido el 18 de diciembre de 2019; aprobado el 17 de noviembre de 2020.

** ORDCID: 0000-0002-6567-2655. Grado académico: Posgrado lato sensu en Gestión de Negocios por la Pontificia Universidad Católica de Minas Gerais; licenciado en derecho por la Universidad Federal de Juiz de Fora; licenciado en administración por el Instituto Metodista Granbery. Adscripción académica: Abogado en el área de delitos eco-

Boletín Mexicano de Derecho Comparado, nueva serie, año LIII, núm. 158, mayo-agosto de 2020, pp. 685-732. 
SUMARIO: I. Introducción. II. La relevancia y expanción del interés científico acerca de la corrupción en el sector privado. III. El marco legal internacional y regional en la lucha contra la corrupción en el sector privado. IV. El panorama legislativo brasileño sobre la corrupción en el sector privado. V. Conclusión. VI. Referencias.

\section{INTRODUCGIÓN}

Aunque haya reconocimiento por parte de la academia, de organismos internacionales y de muchas naciones acerca de los efectos puramente negativos de la corrupción en el sector privado para toda la sociedad, que es suficiente para justificar la persecución penal, civil y administrativa de dicha conducta, muchos ordenamientos jurídicos, sobre todo los sudamericanos, aún tratan la corrupción como un fenómeno asociado exclusivamente al sector público.

Dada la amplitud y complejidad del estudio acerca de la corrupción, sin duda uno de los temas menos explorados se refiere a su ocurrencia en el sector privado que sigue siendo un problema multifactorial cuya amplitud de su planteamiento alcanza muchas medidas importantes en la lucha contra la corrupción, tal como el gobierno corporativo ético, la integridad corporativa, la protección de informantes entre otros. La presente investigación se centra en una de estas muchas medidas que es el aspecto penal del combate a la corrupción en el sector privado, más específicamente la necesidad de tipificar delitos como el cohecho entre particulares o el trafico de influencia entre particulares.

Hay que señalar que la lucha contra la corrupción privada no se limita a la necesidad de tipificar las conductas de los particulares que implican corrupción como delitos cuyo sujeto activo y pasivo son empresas privadas o particulares, ya que se reconoce que hay muchos otros aspectos a discutir en torno a una lucha efectiva contra el fenómeno en estudio, sin olvidar que la criminalización de las acciones entre particulares es un elemento necesario, pero no suficiente para lograr combatir la corrupción privada. También es importante destacar que el desarrollo de este tema es limitado a exponer las carencias en materia de regulación de los delitos en

nómicos y compliance anticorrupción. Líneas de investigación: Derecho Penal, Economía y Empresa; Lavado de Capitales y delitos fiscales, y Corrupción, delitos económicos y políticas de integridad. Correo electrónico: carlosgodoi@me.com.

Esta obra está bajo una Licencia Creative Commons

Atribución-NoComercial-SinDerivar 4.0 Internacional, IIJ-UNAM.

Boletín Mexicano de Derecho Comparado, núm. 158, mayo-agosto de 2020, pp. 685-732. 
Brasil en particular y en América latina en general a partir de un análisis de derecho comparado principalmente con Europa.

No se hace un análisis sobre la calidad de la regulación o las buenas y malas prácticas en legislaciones penales de la región respecto de los delitos de corrupción porque sobrecargaría demasiado la delimitación del objeto de estudio, que considera tema para otro artículo dedicado a analizar los diferentes modelos de tipificación de la corrupción entre particulares como delito en los diferentes ordenamientos jurídicos nacionales. Sin embargo, se hace un análisis del grado de eficacia en la persecución de estos delitos de corrupción en el sector privado y se está relacionado con la forma de legislarlo.

La estructura argumentativa de este estudio buscar articular el tema a partir de la comprensión de la amplitud y complejidad de la corrupción dentro de la dicotomía público-privado, de manera que se llegue al concepto del fenómeno a que se pueda definirse en su variante puramente privada para que sea posible hacer aportes respecto a su relación con la normatividad mencionada y su utilidad para comprender casos concretos. Además, no se puede alejar del análisis teórico de la corrupción privada la breve discusión acerca de sus efectos y costes económicos, sociales, políticos y empresariales, para que sea posible comprender su relevancia científica y, en consecuencia, la necesidad de esta investigación.

Una vez establecido el marco teórico, la discusión pasa al ámbito legislativo, con un enfoque predominante del derecho comparado, partiendo de un recorrido histórico sobre el planteamiento normativo de la corrupción en el sector privado, desde sus escasos avances en la agenda internacional, que está mayoritariamente permeado por tratados y convenciones diseñados para combatir la corrupción que involucra al sector público, hasta el papel de los organismos regionales en la contribución a la aceleración del proceso de tipificación de las conductas entre particulares relacionadas a la corrupción como delitos en las legislaciones de los países. Para ello, el segundo apartado ofrece un análisis descriptivo de la criminalización de la corrupción privada en el contexto europeo en comparación en el latinoamericano, que son profundamente distintos.

El tercer apartado articula los aspectos normativos del caso brasileño, teniendo en cuenta todos los antecedentes discutidos, buscando delinear la etapa brasileña de criminalización de la corrupción privada, discutiendo las propuestas legislativas vigentes, analizar los pros y contras del enfo- 
que punitivo para la lucha contra la corrupción privada según el panorama brasileño y acotar los aportes a la parte de la legislación penal.

La metodología de investigación adoptada en el presente trabajo se basa en un análisis exploratorio acerca de los estudios académicos sobre el tema y un análisis descriptivo sobre como las teorías se aplican en el plan fáctico en la realidad normativo-político brasileño. En relación con el delineamiento de la investigación, esta se desarrolla por medio de investigación bibliográfica en las publicaciones notablemente respetadas y las más recientemente producidas, asó como la investigación documental en las producciones legislativas domésticas y los tratados internacionales sobre el tema de la corrupción entre particulares.

La tesis planteada en este artículo busca responder las siguientes cuestiones: ¿qué importancia tiene el marco penal en una amplia gama de medidas para luchar contra la corrupción privada? ¿La criminalización de la corrupción privada puede considerarse un elemento necesario y suficiente para lograr combatir la corrupción? ¿Cómo se aborda la criminalización de la corrupción privada a nivel regional e internacional? ¿Cómo es la etapa de enfrentamiento penal de la corrupción privada en Brasil en comparación con otros países? ¿Cuáles son los aportes a la parte de la propuesta legislativa penal sobre la corrupción privada en Brasil? ¿Cuáles son los efectos extralegales que pueden resultar de la falta de criminalización de la corrupción privada en Brasil?

\section{LA RELEVANCIA Y EXPANCIÓN DEL INTERÉS CIENTÍFICO AGERCA DE LA GORRUPCIÓN EN EL SEGTOR PRIVADO}

La corrupción, no importa cuál sea su modalidad, es uno de los delitos más difíciles, se no es el más difícil de investigar, pues, en la mayoría de las veces, ella realizase en absoluto secreto y con medios sofisticados orquestados por sujetos que saben ocultar con maestría los rastros de sus acciones y enterrar el fruto de sus delitos, por veces allá de cualquier investigación (Hershman 1996, 62).

La complejidad en torno a la naturaleza de la corrupción hace con que este fenómeno sea dificilmente explicado o definido y este problema no se limita al aspecto semántico (Aidt 2003, 636), sino que a su multifacético carácter que es reflejado en una pluralidad de combinaciones de 
conceptos y definiciones en la misma proporción que la cantidad de áreas donde ha producido la corrupción, sin llegar a un solo concepto capaz de contemplar todas sus variantes (Riccardi y Sarno 2014, 630-641), teniendo en cuenta que aún existe desacuerdo en la literatura sobre este tal concepto definitivo, analítico, completo y formal (Tanzi 1998; Shleifer and Vishny 1993; Senturia 1931).

Este escenario multifacético de complejidad en torno a la corrupción tiene en todas sus ramificaciones una raíz común que asume un fundamento en sistemas dinámicos donde no existen reglas deterministas y los elementos que componen el sistema, interactúan entre sí y con el entorno. Queda por enfatizar que la complejidad no puede reducirse sólo al aspecto conceptual de la corrupción, sino que se extiende a toda la órbita de su entendimiento que incluye la dificultad de medirla, por ejemplo (Byrne 1998, 32).

Así, la complejidad puede entenderse tanto como una causalidad de los sistemas, que resulta en su calificación - por tanto, sistemas complejos - como a lo que es producido por los sistemas complejos, que es efecto, los convierten en sistemas no lineares, es decir, que no mantienen correlaciones de causalidad, y por eso que cambian constantemente (Folloni 2016, 31). Esta característica de contingencia explica por qué pequeños cambios en los elementos que componen un sistema pueden generar cambios en el conjunto, en un efecto mariposa predicho por Lorenz (1972) en la teoría de la sensibilidad a las condiciones iniciales, según el cual ligeros cambios en las condiciones iniciales de un sistema pueden resultar en cambios sustanciales en patrones finales, en un proceso caótico en el que el sistema, aunque dinámico, se relaciona con el entorno y a partir de estas interacciones entre los elementos del sistema y estos y el entorno, en consonancia con su capacidad de auto organización, es donde encuentra su camino.

Resulta que estas interacciones pueden ser tanto positivas como negativas, generando perturbaciones de las cuales emergen interacciones más complejas, subsistemas o incluso otros sistemas complejos, y en este contexto, estas interacciones permiten el mantenimiento y supervivencia de los sistemas, ya que permite su ajuste mediante la adaptación a nuevos comportamientos (Biase 2010, 3). Sin embargo, a pesar de la característica de auto organización de los sistemas complejos, sus constantes mutaciones reflejan su inestabilidad debido a problemas internos de sus 
elementos, pero principalmente debido a la necesidad de adaptarse al entorno (Gunther 2011, 68).

A pesar de las múltiples variables, los sistemas complejos no son contradictorios, sino adaptativos, moldeando y adaptando el comportamiento de sus elementos a través de algún tipo de aprendizaje, que en la perspectiva de las acciones delictivas, la estructuración del crimen organizado, como suele ocurrir en los delitos económicos y cuello blanco, se desarrolla de manera no lineal y con diversos grados de complejidad que varían según los diferentes contextos internos y externos, por lo que sus elementos asumen una auto organización que impacta en la reestructuración de la actividad delictiva para adaptarse y continuar operando (Beato y Zilli 2012, 79).

Por esta razón, la corrupción como elemento de un sistema adaptativo complejo funciona ordenando el sistema caótico a través de la articulación y rearticulación de sus fuerzas a intereses económicos específicos de vez en cuando, razón por la cual las actividades delictivas son constantemente sofisticadas para adaptarse y sobrevivir a la crisis. Actuación de las autoridades que desequilibran el sistema cuando descubren los esquemas de corrupción.

Esta complejidad va mas allá de la estructuración de actividad delictiva, a menudo organizada, ya que parte del concepto mismo de corrupción, que se percibe en toda la literatura académica específica que define su concepto desde una perspectiva económica, como un fenómeno de decadencia moral y falta de ética (Huntington 1968), asociado con en el gobierno y la burocracia (Rose-Ackerman y Palifka, 1999), o mismo relacionado con un contexto de insuficiente crecimiento económico o modernización (Nye 1967). Modernamente, la corrupción también se define dentro del marco civilizacional y culturalista (Inglehart y Welzel 2005; Putnan 2006) y desde una perspectiva de elección racional individual dentro de un sentido colectivo (Juraev 2018; Ferejohn y Pasquino 2001), siendo posible encontrar dentro de un contexto social, la clasificación de la corrupción en tipos y subtipos apuntando a una comprensión más operativa, como la clasificación de la corrupción en función de su magnitud económica con conceptos como gran corrupción, corrupción estructural, corrupción sistémica o endémica, corrupción menor (Andvig et al. 2001) y el rentismo (Khan y Jomo 2000). 
Aunque la corrupción esté bajo a este panorama desafiante, el fenómeno ha atraído crecientemente la atención de la academia ante a su complejidad en términos social, político y económico, cuyos impactos son sentidos por todas las naciones del mundo, independiente del régimen de gobierno - sea autoritario o democrático - y del sistema económico sea capitalista o socialista-, en un grado mayor o menor a depender de la fuerza y fiabilidad de las instituciones (Robles 2015, 12).

Desde una perspectiva clásica de la corrupción, la literatura mayoritaria la concibe como un fenómeno cuyo sustrato está arraigado en el sector público, suponiendo una desviación en torno a la actividad económica de la administración pública, a la utilización desleal de las potestades públicas de decisión, control y aplicación de fondos públicos, que debería guiarse por los principios de la legalidad, impersonalidad, probidad publicidad, eficiencia y, sobre todo, de la primacía del interés público, para beneficiar a los intereses privados o particulares del titular de esas potestades o de uno o varios terceros relacionados con él mediante relaciones económicas ilícitas o de confianza que contraria la cláusula constitucional del Estado social de derecho, según la cual todos los intereses privados quedarán supeditados al interés general de la nación (Cascón 2012, 283).

En la base de este concepto teórico, la corrupción es comprendida como un problema relacionado con el conflicto de intereses públicos o generales e intereses privados o particulares, generalmente asociados a la maximización de lucros empresariales y privados, que se interponen a aquellos, aprovechando comportamientos desviados, o mismo omisiones, de quienes tienen competencias de gestión y representación de administraciones y entes públicos con potestades públicas, que puede ser provocada por decisión propia o fomentada por un tercero ajeno a la administración que pretende valerse del poder del titular de las potestades públicas ofreciendo a cambio dádivas o ventajas con sustrato económico (Motta y Belém 2018, 151), distinguiéndose así en la tradicional clasificación entre corrupción activa (el que soborna) y corrupción pasiva (el que es sobornado), que es un modelo ampliamente un modelo ampliamente instituido por las leyes penales de diferentes ordenamientos jurídicos, además de estar ratificado en tratados y convenciones internacionales como mandado mínimo imperativo ser internalizado en los sistemas normativos nacionales, como por ejemplo el artículo 4o., parágrafo primero, con artículo el 5o. de la Convención Interamericana contra la Corrupción, 
los artículos 15 y 16 de la Convención de las Naciones Unidas contra la Corrupción, el artículo 1o. de la Convención para Combatir el Cohecho de Servidores Públicos Extranjeros en Transacciones Comerciales Internacionales y el artículo 4o., parágrafo primero, con el artículo 5o. de la Convención sobre la Prevención y Lucha contra la Corrupción de la Unión Africana.

En el ámbito académico, los conceptos clásicos de corrupción ligados al prisma político se pueden encontrar en teorías que asocian el fenómeno a la falta de institucionalización de los conflictos entre las personas (Aristóteles 1905; Maquiavelo 1981), que lo asocian con la iniquidad del gobernante o la ausencia de poder divino (Montesquieu 1823), que lo conciben como el fracaso del soberano en asegurar la obediencia de sus súbditos (McGing 2010), y que lo considera como la degeneración de las costumbres de una sociedad política (Hobbes 1968; Rousseau 1974; Tocqueville, Mansfield y Winthrop 2000).

La corrupción ha sido objeto de una serie de estudios en varias áreas de investigación, tal como la economía, especialmente en lo que respecta a sus efectos sobre el desarrollo, y el derecho, sobre todo cuanto a sus aspectos penales y en el ámbito de la persona jurídica, orientándose por diversas perspectivas teóricas, sea de los derechos humanos, de la psicología, de la criminología o de la ética (Cuenca 2009, 27).

A partir del momento en que la teorización de la corrupción rompió con la concepción según la cual el fenómeno consiste en el abuso del poder o irregularidad en el proceso de toma de decisión político o administrativo para adoptar una visión basada en el uso de una posición de poder para lograr una ventaja indebida, el estudio de la corrupción empezó a dedicarse no sólo a la corrupción en el sector publico, sino también en el sector privado hasta que la corrupción privada alcanzase la autonomía teórica (De la Cuesta Arzamendi 2014, 4).

En vista de las distintas dimensiones de la corrupción respecto al público y al privado, de acuerdo con las lecciones de Argandoña y Berendson (2009, 8), afirmase que:

Debido a la cobertura que ha tenido la corrupción en el sector público, son de sobra conocidos los ejemplos de acciones corruptas en dicho ámbito, como los pagos para que un político o funcionario autorice la concesión de un contrato público; sin embargo, muchas veces resultan menos conocidos 
los ejemplos del sector privado - aunque cada vez suenan más-, como las atenciones al director de compras de una empresa para conseguir un pedido o, simplemente, para tener su ánimo inclinado a concederlo en el futuro. Se trata de prácticas que no siempre se pueden distinguir de la costumbre legítima de hacer regalos para mantener buenas relaciones comerciales y sociales.

Los avances en los estudios sobre la corrupción en el sector privado han demostrado que hay varios ejemplos en lo que verificase hechos de corrupción cometidos exclusivamente entre sujetos privados, tales como el soborno de un empleado de un banco para que conceda un préstamo a una empresa en condiciones favorables, el incentivo indebido de los directivos o empleados de una entidad con el fin de obtener una licencia y el cambio de la ingeniería de un procedimiento de contratación de una empresa mediante el pago de soborno (Argandoña 2005, 8).

Además del reconocimiento del universo privado que redoma la corrupción, los estudios científicos también han demostrado que dicho fenómeno produce efectos negativos sobre bienes jurídicamente tutelados y que están íntimamente relacionados al orden económico que son la debida lealtad al propietario de la empresa o al empleador, la protección del patrimonio de la empresa, la protección del consumidor y la justa competencia en el mercado (Encinar del Pozo 2016, 91).

La corrupción ejerce efectos nefastos en la economía y la academia asume dos corrientes teóricas que relacionan la corrupción con el crecimiento económico. La primera es la corriente revisionista que defiende que la corrupción puede ser benéfica para la economía (Leff 1964; Huntington 1968) y la segunda es la corriente rent-seeking que destaca la relación negativa entre la corrupción y la economía (Carraro, Fochezatto y Hillbrecht 2006; Fiorino, Galli y Petrarca 2012).

La corriente revisionista tiene sus raíces en la escuela funcionalista y en líneas generales comprende la corrupción como un mal necesario en los países en desarrollo económico hacia la modernización, pues la corrupción funciona como un dinamizador necesario al avance de los negocios. Esta posición es planteada en el marco de la teoría de la modernización para la cual el soborno conduce a un mejor bienestar económico, ya que suprime la carga de las regulaciones burocráticas, acelerar tramitaciones que involucran las empresas y solucionar el problema de mala remuneración de los burócratas corporativos (Myrdal 1997, 406). Estos 
efectos también se extienden a la apertura del mercado a nuevos entrantes, ya que considera que la corrupción reduce las incertidumbres sobre los resultados y reduce las barreras de acceso a los proyectos de inversión, además de ser un factor de ser un factor de incremento a la eficiencia del sistema económico, ya que, al estimular la competencia en el mercado, genera una ventaja competitiva en el largo plazo para las empresas debido a costos de producción más racionalizados (Leff 1964, 9).

De acuerdo con Huntington $(1968,70)$, el proceso de modernización económica de las sociedades introduzco nuevos valores que confrontaron las antiguas estructuras económicas, incrementó el movimiento de recursos en el mercado, generó nuevos centros de poder y creó nuevas oportunidades y incentivos al crecimiento económico, que no necesariamente son benéficos para los negocios, por lo que en este contexto la corrupción puede acelerar trámites burocráticos y permitir que las empresas eviten el retraso. Leff $(1964,10)$ romantiza la corrupción llamándola practica de speed money que permite a los particulares evitar la burocracia en los tramites que retrasan los negocios y hace con que los sobornados trabajen de manera más eficiente, ya que los sobornos sirven para estimular su productividad.

Osterfeld $(1992,273)$ es más moderado y a pesar de asumir la defensa de un carácter expansivo de la corrupción con relación a los negocios con efectos positivos sobre la competitividad y flexibilidad de la economía, considera los efectos negativos de la corrupción asociados a su carácter restrictivo que limitan las oportunidades de intercambios productivos en el mercado y estimula por consecuencia la permanencia de empresas ineficientes. Huntington $(1968,71)$ también admite que la corrupción puede tener un efecto inverso en el mediano plazo, porque en lugar de evitar una regulación excesiva e ineficiente, viola sistemáticamente la orientación económica hacia la ineficiencia.

La corriente rent-seeking concibe la corrupción como un obstáculo al desarrollo económico de la sociedad con efectos negativos sobre la eficiencia del mercado, ya que desperdicia los recursos, distorsiona el proceso de toma de decisiones sobre inversiones y concentra la distribución de renta en las manos de los corruptos (Rose-Ackerman 1996, 3). La falsa percepción de que la corrupción permite superar las regulaciones burocráticas sólo perdura en el corto plazo, pues la corrupción pronto adquiere una proporción sistémica que termina desperdiciando recursos que podrían

Esta obra está bajo una Licencia Creative Commons

Atribución-NoComercial-SinDerivar 4.0 Internacional, IIJ-UNAM.

Boletín Mexicano de Derecho Comparado, núm. 158, mayo-agosto de 2020, pp. 685-732. 
invertirse en innovaciones y nuevos negocios y compensando el costo de la corrupción en el precio relativo de los productos y servicios (Alam 1991, 90). La corrupción también lleva a la politización de la asignación de recursos, y en este aspecto la politización no está vinculada con el sector público, sino que en su sentido más amplio, que significa que la transferencia de renta se concentra entre los burócratas y los que les apoyan, lo que resulta en contrataciones que ya no exigen eficiencia pero que se basan en la cantidad de soborno que paga, retornan al mercado productos y servicios de baja calidad y sectores de mercado donde el soborno es facilitado y por eso la probabilidad de detectarlo es más baja (Mbaku 1992, 249).

Los efectos negativos de la corrupción también alcanzan el comercio internacional, ya que las empresas exportadoras radicadas en países industrializados que pagan sobornos en cambio de un ingreso facilitado en mercado menos desarrollados económicamente, generando un patrón de pagos soborno institucionalizado como una etapa de los negocios mucho conocida como tarifa de facilitación, lo que promueve una cultura de ilegalidad y fomenta la ineficacia del mercado que son pagos en ultima instancia por los consumidores en precios más elevados por productos y servicios con menor calidad, razón por la cual los organismos internacionales con actuación en el comercio y las finanzas internacionales como la Organización Mundial del Comercio y el Fondo Monetario Internacional empezaron a establecer regulaciones para la prevención y detección de corrupción (Carnegie Endowement for International Peace 2002, 2).

Por lo tanto, las economías de los países corren grave peligro de que la corrupción alcance una proporción sistémica, que de un medio para obtener un trato privilegiado a la empresa en detrimento de los demás competidores se convierte en una especie de "impuesto" sobre la actividad empresarial, lo que en el mediano y largo plazo conllevará costos operativos que irán más allá del soborno pagado, ya que incluye en esta suma los costos indirectos relacionados con el mantenimiento del secreto sobre la práctica corrupta, el blanqueo de activos vinculados a las transacciones ilícitas que, al fin y al cabo, resulta en un impacto negativo en la capacidad financiera de la empresa y su supervivencia en el mercado (Furtado 2012, 43).

Estos costos implicados cuando la corrupción es llevada a cabo por la empresa también son concebidos por la escuela del análisis económico del derecho como costes de transacción (Coase 2008, 12), partiendo de la pre- 
misa de que cualquier interacción entre sujetos implica costos, considerado también como costos de operar la actividad delictiva (Olken y Pande 2012, 500; Becker 1968, 179). Estos costos van mucho más allá del propio soborno, ya que se relacionan más con las consecuencias secundarias, que pueden ser clasificados como directos, de fácil estimación y control - por ejemplo, multa, encarcelamiento etcétera- e indirectos, de difícil valoración y control - por ejemplo, reducción de la transparencia, cultura organizacional corrupta etcétera- (Argandoña 2007, 4).

La corrupción entre particulares es perjudicial a todos, incluso aquellos no involucrados en tramas corruptas, pues además distorsionar los precios practicados en el mercado, aumenta los costos de hacer negocios repasados en los contratos, introduce una incertidumbre significativa en las operaciones comerciales debido a la tendencia de inflación constante en los pagos de soborno, socava la confianza de los empleados en la gestión de la empresa y promociona un ambiente corporativo permisivo a la corrupción de manera sistémica dentro de la empresa (U.S. Department of Justice y U.S. Securities and Exchange Commission 2017, 3).

Las ventajas inmediatas de la corrupción son poco sostenibles y muy costosas a largo plazo, pues las empresas se descuidan de sus ventajas duraderas que las hacen permanecer en el mercado en medio a la competencia y que están asociadas a la calidad e innovación en productos y servicios. Inicialmente la corrupción coloca las empresas en una zona de confort, haciéndoles creer que los sobornos son los que garantizan las transacciones comerciales, pero terminan perdiendo espacio por el rezago tecnológico y de calidad con relación a sus competidores provocado por el enfoque en actividades corruptas (Argandoña y Berendson 2009, 12).

Los efectos de la corrupción a las empresas pueden ser analizados desde una perspectiva financiera sobre la relación entre el soborno y otros pagos ilícitos y la tasa impositiva marginal. En el primer momento el soborno reduce las tasas impositivas — que serían pagas en el ejercicio regular de la actividad empresarial-, por lo que la tasa marginal del soborno debe ser menor que la tasa impositiva para darle ventaja. En el segundo momento el soborno deja de ser sólo un instrumento para evitar las tasas impositivas para convertirse en un medio para obtener negocios privilegiados y facilitados, y con el aumento de los sobornos la tasa marginal crece por encima de la tasa impositiva y la empresa ya no tiene más las ventajas financieras de la corrupción (Olken y Pande 2012, 493).

Esta obra está bajo una Licencia Creative Commons

Atribución-NoComercial-SinDerivar 4.0 Internacional, IIJ-UNAM.

Boletín Mexicano de Derecho Comparado, núm. 158, mayo-agosto de 2020, pp. 685-732. 
La primera idea sobre la tasa impositiva es el impuesto, lo cual es cierto, pero hay una serie de tasas impositivas que no son oficiales, es decir, que no están calificadas como especies tributarias, tales como, por ejemplo, interés contractual, tarifas de operación, entre otras. No necesariamente los fraudes que objetivan la evasión fiscal involucran un agente del sector publico cómo partícipe de la trama corrupta, sino que puede ser practicada en colisión entre particulares, tal como, por ejemplo, una empresa que acepta el pago de soborno - sujeto pasivo - de otra empresa - sujeto activo - para fraudar las facturas de venta a una tasa marginal menor de lo que pagaría a las autoridades fiscales, eso sin pagar cualquier soborno a un funcionario público. En esta hipotética situación, el Estado es la víctima directa de la trama de corrupción privada, pero no hay que olvidar que las demás empresas competidoras en el sector privado también son víctimas indirectas de la práctica de competencia desleal orquestadas por las empresas corruptas.

La empresa donde trabaja el sujeto pasivo del soborno no siempre está en colusión con el sujeto activo del cohecho y puede ser victima del delito. Muchos esquemas de corrupción están ocultos a la empresa por los gerentes involucrados en el fraude y la empresa termina pagando la compensación del soborno en contratos sobrevalorados, reduciendo su capacidad competitiva en el mercado y en muchos casos traspasando estos costos a los consumidores. De acuerdo con el Banco Mundial, la inflación de precios contractuales puede alcanzar niveles de diez al quince por ciento en determinados sectores de mercado para la obtención de negocios y una décima a dos décimas por ciento sobre los ingresos para la manutención de los negocios (Kenny 2006, 5).

Otro efecto de la corrupción sobre las empresas puede ser sentido cuando las tramas de corrupción son desveladas por las autoridades y tornase pública y notoria con serios perjuicios a la imagen corporativa que se puede sentir en la devaluación de valores cotizados en bolsa, represalias de los consumidores, recisión de contractos comerciales, etcétera. La reputación de las personas jurídicas es susceptible a una rápida devaluación por una serie de factores desde posturas socialmente objetables hasta la participación en actos ilegales y, en muchos casos, la pérdida de credibilidad es irreversible, pues las consecuencias de la corrupción sobre la imagen corporativa llegan a ser peores que las sanciones judiciales, ya que la recuperación/reconstrucción de la reputación de la empresa además de 
requerir inversiones muy elevadas y dependiendo de la receptividad o percepción del mercado la reconstrucción de la identidad corporativa puede resultar irrecuperable (Martínez, Juanatey y Blázquez 2004, 49).

Cuando se hacen públicos los casos de corrupción que involucran a empresas, se debe tener en cuenta el aspecto extraterritorial de la legislación anticorrupción en ciertos países (por ejemplo, la Ley de Sobornos del Reino Unido y la Ley de Prácticas Corruptas en el Extranjero de EE. UU. - aunque esta no prevé el delito de corrupción privada-) donde la empresa opera comercialmente, ya que la persona jurídica puede estar sujeta a sanciones de diferentes jurisdicciones, multiplicando el daño a los activos de la empresa.

Además del daño a la propiedad, se daña el patrimonio humano de la empresa, ya que el descubrimiento de esquemas de corrupción altera la percepción de los empleados sobre la organización, produciendo tres posibles resultados: quienes buscan nuevas oportunidades para aprovechar las prácticas corruptas por el sentimiento de permisividad, los de baja productividad por la sobreviniente incompatibilidad con los valores corporativos y la fuga de profesionales altamente calificados que no quieren vincularse a la empresa para no empañar el currículum (Argandoña y Berendson 2009, 13).

La literatura académica con todos estos estudios señala la debilidad de argumentos desfavorables al reconocimiento normativo penal de la corrupción en el sector privado encampados en el dogma liberal de que el mercado es una entidad eficiente para mitigar por sí solo la corrupción o de que la corrupción en el sector privado produce ínfima lesión a los bienes jurídicos que no justifica la tutela del Estado.

Así, la corrupción no es un fenómeno restricto al sector público, extendiéndose a otros ámbitos de la vida social cómo un fenómeno social complejo que es, con especial destaque para su manifestación en el sector privado, cuyos efectos, mientras afecten no sólo la economía mas perjudica el regular funcionamiento de las instituciones sociales, tiene poco reconocimiento acerca de su relevancia en el escenario legislativo de los países, especialmente los americanos (Bardón 2013, 3). 


\section{EL MARCO LEGAL INTERNAGIONAL Y REGIONAL EN LA LUCHA CONTRA LA CORRUPCIÓN EN EL SECTOR PRIVADO}

El derecho penal moderno es orientado por el principio del carácter ofensivo que consiste en la evaluación de las posibles lesiones o el riesgo de lesión del bien legal protegido con el fin de verificar la relevancia penal de la conducta para justificar su criminalización. Este principio diseña un modelo de derecho penal que no admite la existencia de un delito sin ofender a un patrimonio legal, es decir, no hay delito cuando la conducta no ha ofrecido el menor peligro de daño al bien legal, siendo así un requisito de delimitación del derecho penal, tanto a nivel legislativo como judicial (Gomes 2007, 464).

Desde del principio del carácter ofensivo, áreas donde la criminalización tiene pocos beneficios sociales se justifica la despenalización de conductas, especialmente se existen otros instrumentos suficientemente efectivos, tales como las sanciones civil y administrativa, así como códigos de ética en el marco de las empresas y sectores del mercado (Rose-Ackerman 2002, 5), lo que remite a otro principio, el de la ultima ratio del derecho penal, también conocido como principio de la intervención mínima o de subsidiariedad, según el cual el derecho penal sólo puede ser utilizado por el Estado como el ultimo recurso para proteger bienes jurídicos, cuando otros órdenes jurídicos han resultado insuficientes, es decir, la actuación estatal está subordinada a la verificación de su necesidad, conveniencia de una acción a esa escala e insuficiencia de las políticas estatales (Rodríguez 2008, 16).

Es inequívoco que el derecho penal es la rama del derecho utilizada predominantemente por los Estados como un instrumento destinado a reprimir comportamientos ilícitos como la corrupción. Este escenario se traslada a los tratados internacionales sobre la lucha contra la corrupción y el crimen organizado, que en su mayoría enumeran una orden de criminalización como obligación única o mezquina. En otras palabras, los Estados encuentran en el ámbito internacional más compromisos para tipificar conductas como delito que brindar respuestas alternativas más efectivas en el ámbito civil y administrativo.

El derecho penal es una herramienta necesaria en la lucha contra la corrupción, pero mientras sea imprescindible, no lo es de forma aislada, sino que debe ser concebido como uno entre otros instrumentos de do- 
ble función preventivo-punitivo, pues el derecho por sí solo es incapaz de acabar con la corrupción, pero puede y debe contribuir a la tarea (García 2015, 30). Superando las fronteras del derecho penal, el análisis de la corrupción no está restricto a esta rama del derecho, sino que encuentra una respuesta eficaz desde un plan económico, político, sociológico, desde su incidencia en las relaciones internacionales o mismo desde distintas perspectivas jurídicas.

Aunque la corrupción tiene una dimensión sobre todo sociológica y política, el fenómeno puede y debe ser abordada desde el terreno de la ciencia jurídica que tradicionalmente es objeto de atención del derecho penal y administrativo en figuras delictivas tales como delitos contra la administración pública, societarios y contra el mercado, régimen de incompatibilidades de los funcionarios públicos, responsabilidad patrimonial de la administración etcétera. Sin embargo, es importante señalar que cuando en el Código Penal se agrupan los comportamientos de corrupción incriminado bajo el título de "Delitos contra la Administración Pública", sólo se tiene en cuenta la corrupción en el sector público. Por tanto, no la que consiste en actos en los que tanto el corrompido como el corruptor pertenecen al sector privado.

Dotti (2003, 315) y Castillo (2005, 111$)$ afirman que el grado de constricción de los derechos fundamentales por parte del derecho penal la convierte en la rama de la ciencia que más presta atención al cumplimiento de los principios de legalidad y anterioridad (regla ex post facto). Ambos autores afirman que estos principios aportan un mayor nivel de seguridad jurídica a la sociedad debido a la regla obligatoria de descripción exhaustiva y específica de las conductas consideradas delitos y la previa definición normativa de la conducta como delito y de sus penas ante la sanción del individuo, evitando la creación de tribunales de excepción.

Así, el derecho penal es conceptualizado por parte predominante de la academia como una herramienta necesaria para combatir la corrupción, a pesar de su reconocida incapacidad para eliminar por sí misma la práctica de los delitos, pues delitos de esta naturaleza y gravedad requieren una mayor constricción sobre los derechos individuales de la persona condenada por el acto antijurídico imputado y sirve como disuasivo de conductas ilícitas (Del Moral García 2015, 30 y 31).

En el derecho internacional existe una consagración de la responsabilidad penal de la persona natural involucrada en la práctica de la corrup-

Boletín Mexicano de Derecho Comparado, núm. 158, mayo-agosto de 2020, pp. 685-732. 
ción como una cláusula imperativa de un tratado como puede verse en la Convención de Mérida de Naciones Unidas sobre la Corrupción (artículos 15, 17 y 23), el Convención sobre el Cohecho de Servidores Públicos Extranjeros en Transacciones de Comercio Internacional de la Organización para el Desarrollo y la Cooperación Económica (artículos 1o., 3o. y 7o.) y la Convención Interamericana contra la Corrupción de la Organización de los Estados Americanos (artículos 6o., 8o. y 9o.), por ejemplo.

En este sentido es valido señalar las lecciones de Rose-Ackerman 2002, 18):

El derecho penal puede disuadir la corrupción de varias formas. En primer lugar, puede ser necesario reexaminar el derecho penal sustantivo para determinar si algunas actividades privadas podrían despenalizarse, reduciendo así la corrupción y la participación del crimen organizado. Alternativamente, algunas actividades actualmente aceptables, como los conflictos de intereses, pueden necesitar ser reguladas o prohibidas. En segundo lugar, las sanciones por pagar y recibir sobornos deben reflejar las ganancias marginales de los sobornadores y los receptores de sobornos. El primero debe ser penalizado en proporción a los beneficios que posibiliten los sobornos; esto último en términos de los beneficios de los propios pagos. En tercer lugar, dado el nivel de antecedentes de las sanciones, los fiscales y los investigadores deberían poder recompensar a quienes brinden información útil que ayude a las autoridades a descubrir redes corruptas ocultas. Esto a menudo implicará hacer tratos con aquellos que han pagado y recibido sobornos en el pasado. En cuarto lugar, las cuestiones de responsabilidad individual no deben disuadir a los reformadores de la ley de encontrar formas de responsabilizar legalmente a las organizaciones como corporaciones por los actos corruptos de sus agentes. Esto puede implicar responsabilizar penalmente a las organizaciones, pero es posible que se obtengan resultados similares con sanciones puramente civiles, siempre que puedan estar vinculadas a actos corruptos relacionados con las actividades de la empresa. Finalmente, a menudo se necesitarán esfuerzos especiales para contrarrestar la influencia del crimen organizado, especialmente cuando opera a escala internacional: se necesita la cooperación internacional para enredar redes corruptas y recuperar el producto de negocios ilegales.

Esta investigación no intenta debatir sobre la responsabilidad penal de la persona jurídica, pues sería un tema más extenso que carece de un estudio dedicado a sus complexas cuestiones. Lo que se intenta es com- 
prender en un primer momento la corrupción privada como el cohecho operado en el ámbito privado entre particulares, sin la participación de un agente público. Sin embargo, es importante mencionar que la efectividad de la respuesta criminal del Estado contra la corrupción y los delitos económicos en general han sido cuestionados por una parte creciente de la academia, especialmente en relación con las personas jurídicas. En las últimas décadas se ha prestado atención a los criminalistas a la conexión casi indispensable entre los delitos de cuello blanco y las empresas cuya complejidad puso en cuestión la base clásica de las teorías criminales que fueron conceptualizadas para examinar la conducta individual de las personas naturales (Schünemann 1988, 529-531).

Respecto a la dicotomía entre el público y el privado es importante destacar que la simple separación entre estas esferas consiste en una simplificación demasiado bruto de la estructura social que encerca la corrupción, así como la idea de fusión de los aspectos del público y del privado es deficiente, pues desconsidera el hecho de que la sociedad es fragmentada en diversos sectores que requieren una multiplicidad de enfoques descriptivos distintos que no suenan ser satisfactoriamente comprendidos por una clasificación binaria.

Esta dicotomía es factiblemente verificado en el trato normativo de la corrupción, donde hay legislaciones que conciben un tipo penal unívoco para abarcar la corrupción en los sectores público y privado y toda la suerte de variables, de modo a ser satisfactorio en alcanzar todas sus distintas formas, al paso que hay otras legislaciones que no se limitan solamente a tipificar la corrupción en dos tipos como corrupción pública y privada, pero importa otros tipos penales que tipifican conductas específicas de acuerdo con su gravedad, tales como soborno de oficiales extranjeros, corrupción deportiva, corrupción urbanística entre otros.

La previsión de la corrupción en el sector privado por diplomas normativos no es reciente, habiendo registros históricos de su criminalización en la Ley sobre la Prevención de la Corrupción de 1906 de Gran Bretaña y en la Ley Contra la Competencia Desleal de 1909 de Alemania. Después de un periodo de olvido de la corrupción en el sector privado entre los temas de interés de los Estados, los cambios en el orden económico de los finales del siglo XX contribuyeron a reavivar los temores acerca de dicho fenómeno por razones importantes: 
El proceso de privatización masiva emprendido en los últimos años del siglo pasado ha supuesto importantes cambios en el sector económico, y una gran parte de las actividades económicas a través de las cuales el Estado cumplía determinadas funciones se ha transferido a empresas privadas. Dado el carácter privado de estas nuevas empresas, si un empleado actúa de forma corrupta como consecuencia de un soborno, no va a poder responder penalmente con base en las normas relativas a la corrupción, pensadas exclusivamente para castigar comportamientos que se llevan a cabo en el sector privado (De la Cuesta Arzamendi y Blanco Cordero 2002, 258).

Hasta comienzos de la década de los noventa, la corrupción era considerada como una materia de jurisdicción doméstica que interesaba tan solamente a los Estados frente su soberanía. Sin embargo, tal escenario empieza a cambiar a partir de los fines de la década de los noventa e inicio del siglo XXI, pues la corrupción en general encampó en la agenda de la comunidad internacional que empezó a tratar el tema mediante instrumentos normativos con mandados imperativos de domesticación legal ante diversos contextos que desafiaron la capacidad de los Estados en frenar los efectos transnacionales del fenómeno, tal como la fuga de capitales y de los agentes para otros Estados y la dificultad para ejecución de sentencias y repatriación de las ganancias y la extradición de los corruptos fugitivos (Vargas 2004, 133 y 134).

Sumase a ese panorama, la apertura de los mercados nacionales y la creciente exigencia por desregulación y modernización de los Estados en vista de atraer inversiones extrajeras, resultando en mayor competencia internacional que por consecuencia demandó a los Estados la adopción de niveles más exigentes de transparencia y prácticas más objetivas y predecibles en las contrataciones públicas con el sector privado, especialmente por fuerza de legislaciones nacionales con efectos extraterritoriales.

Sin embargo, la adopción de nuevas prácticas de buen gobierno no fue capaz de evitar la sofisticación de las prácticas corruptas, debido al carácter complejo del fenómeno, demandando a los Estados una postura más enérgica rumo a la unión de esfuerzos con otras naciones y organismos internacionales de modo a obtener más éxito en el combate a la corrupción. Mismo la corrupción siendo un fenómeno complejo, multifacético y plagado de matices que le confieren un sentido demasiado amplio y metalegal, eso no impidió su integración en el sistema normativo, siendo 
aún paulatina la recepción de sus variables, a ejemplo de la corrupción en el sector privado.

Lo que resultó en el interés internacional por la tipificación de la conducta corrupta entre particulares ha sido una serie de factores enumerados por Antonio Argandoña: los avances en la lucha contra la corrupción en el sector público han puesto de manifiesto la importancia que tiene el fenómeno también en el sector privado, materializado en la Convención de la Organización para Desarrollo y Cooperación Económica (OCDE) que resultó en la reforma de las legislaciones domésticas de sus Estadosmiembros; el aumento significativo de la corrupción en países emergentes para supervivir en medio a la intensificación de la competencia y eficiencia económica de los mercados o de países subdesarrollados para atraer el capital extranjero mediante facilidades ilegales; la sensibilidad de los negocios ante los efectos del soborno y de la extorsión privada sobre la justa competencia; la necesidad de establecimiento de un espacio nivelado para los negocios entre particulares en mercados recién abiertos que aún son conniventes con la corrupción en las costumbres comerciales; la traslación de la cultura de corrupción del sector público para el sector privado en virtud de la privatización de las empresas públicas; los procesos de apertura y desregulación de mercados nacionales sin las necesarias reformas institucionales para que el Estado reúna condiciones para soportar la economía de mercado y la democracia liberal; y, la mayor exposición de los negocios ante la intensificación de prácticas de marketing que resultaron en una valoración mayor por parte de la sociedad a respecto de buenas prácticas y de imagen corporativa (Argandoña 2003, 3).

El protagonismo de la corrupción en las investigaciones académicas en las ultimas décadas reflejó en la agenda política global en la medida en que las organizaciones internacionales han centrado esfuerzos en emprender estudios, esta vez empíricos, con la finalidad de colaborar con las medidas para prevención y lucha contra la corrupción, con especial énfasis en la medición de la corrupción, en el análisis de sus posibles causas y en la creación de recomendaciones de buen gobierno, en particular los provenientes de organismos como la OCDE y el Banco Mundial y de entidades no gubernamentales como la Transparencia Internacional.

Las iniciativas internacionales en materia de lucha contra la corrupción expandieron en el plan normativo al largo de los últimos años debido a la conciencia de su importancia por los actores internacionales, cuyos 
principales instrumentos han sido la Convención de Viena de las Naciones Unidas sobre el Tráfico de Drogas (1988), el Grupo de Acción Financiera (1989), el Convenio de Estrasburgo sobre Confisco y Blanqueo de Capitales del Consejo de Europa (1990), la Directiva 91/308/CEE de la Unión Europea que establece los sujetos obligados a comunicar el origen de sus recursos financieros (1991), la Unidad de Inteligencia Financiera Grupo Egmont (1995), la Convención Interamericana contra la Corrupción de la Organización de los Estados Americanos (1996), el Convenio sobre el Soborno de los Funcionarios Públicos Extranjeros en Transacciones Comerciales Internacionales de la Organización para Desarrollo y Cooperación Económica (1997), el Convenio sobre la Lucha contra los Actos de Corrupción que Involucran los Funcionarios de las Comunidades Europeas y de los Estados Miembros de la Unión Europea del Consejo de Europa (1997), el Grupo de Estados Contra la Corrupción creado por el Comité de Ministros del Consejo de Europa (1998), el Convenio sobre la Lucha contra el Soborno de Funcionarios Públicos Extranjeros en las Transacciones Comerciales Internacionales por el Comité de Ministros del Consejo de Europa (1999), la Convención de Palermo de las Naciones Unidas sobre Delincuencia Organizada Transnacional (2000), la Convención de la Unión Africana para Prevenir y Combatir la Corrupción (2003) y la Convención de Mérida de las Naciones Unidas sobre la Corrupción (2003).

El movimiento de tipificación de la corrupción en el sector privado ultrapasó las fronteras del continente europeo en fines del siglo XX e inicio del siglo XXI, siendo tímidamente recomendado por los organismos internacionales de mayor cobertura a través de instrumentos internacionales de soft law, es decir, que aún no tienen mandados imperativos, sino que un carácter de recomendación no vinculante.

El mejor ejemplo de dicho contexto es la Convención de las Naciones Unidas Contra la Corrupción, también conocida como Convención de Mérida, firmada en el 2003 por una serie de naciones que se comprometieron a prever normas en sus ordenamientos jurídicos que al menos tipificasen penalmente la corrupción y otros hechos delictivos. Sin embargo, a lo que se refiere a la corrupción en el sector privado, existe tan solamente un mandado de criminalización sin carácter imperativo que recomienda el combate a dicha conducta al menos en la esfera civil y administrativa. 
La redacción del artículo 21 de la Convención de Mérida es una clara evidencia de que el consenso internacional es en el sentido de estorbar el avance de la lucha contra la corrupción en un sector estratégico de la sociedad y históricamente poco reglamentado en este sentido, en evidente e innegable trato desigual de la corrupción en el sector público y privado que no sustentase en argumentos validos.

La diversidad de naciones que componen las Naciones Unidas resulta en una inequívoca dificultad para el consenso internacional homogéneo que Sato $(2003,162)$ afirma ser una cuestión históricamente jamás resulta en las relaciones internacionales, pues:

(...) No hay una formula para establecer los límites de la noción de soberanía en confronto con las normas, principios e instituciones internacionales. La razón central reside en el hecho de que no hay un estándar universal para los conceptos de justicia, de derechos y de obligaciones entre sociedades y pueblos. A pesar de toda la retorica de la globalización, continúan evidentes los señales de que permanecen vivas las diferencias culturales y religiosas entre los pueblos. Esas diferencias revelan más una entre las muchas facetas del paradojo de la propia existencia humana: al mismo tiempo que son esenciales para la preservación de la multiplicidad y riqueza del fenómeno humano, también sustentan diferentes patrones de comportamiento económico, social y político, dificultando la comprensión mutua y la convivencia.

En este aspecto de la construcción del orden internacional hay una gran dificultad que reside en la reluctancia de muchos Estados en ceder parte de su soberanía en favor de las instancias internacionales en lo que respecta a la transformación de la acción política doméstica orientada por en consenso multilateral ante las visiones y percepciones internas acerca del mundo y de las cosas.

La opción seguida por la Convención de Mérida difiere mucho de la seguida por los convenios regionales, a destacarse la Convención para la prevención y el combate de la corrupción de la Unión Africana y la Acción Común 98/742/JAI, sustituida por la Decisión Marco 2003/568/ JAI de la Unión Europea, frente a la opción seguida por la Organización de los Estados Americanos (OEA), que refleja la diversidad existente entre los diversos ordenamientos jurídicos que componen la Convención de las Naciones Unidas en punto a la corrupción en el sector privado y el deseo 
de lograr, pese a las diferencias, el mayor numero posible de ratificaciones del texto (Pérez Cepeda y Bento Sánchez 2012, 42).

Históricamente las legislaciones han condicionado su enfoque sobre la corrupción cómo un fenómeno asociado al sector público, alejándose de sus proyecciones en el sector privado, tanto que las definiciones gramaticales del término están vinculados a su carácter público. Sin embargo, el derecho continental europeo camina en dirección opuesta, rompiendo los límites del ámbito público y reconociendo la necesidad de también se castigar la conducta corrupta en el seno de las relaciones privadas. La Decisión Marco 2003/568/JAI de la Unión Europea proporcionó un modelo mínimo de clasificación de la corrupción en el sector privado y aceleró su proceso normativo en el ordenamiento jurídico de los Estados europeos que se ha concretado con la Convención Penal sobre la Corrupción del Consejo de Europa de 1999 que consistió en un marco comunitario de lucha contra la corrupción en el sector privado (De la Cuesta Arzamendi y Blanco Cordero 2002, 261).

Debido a ese motivo, la Convención de Mérida se ha tornado un instrumento internacional sin efectos prácticos en el orden interno de muchos Estados reluctantes en criminalizar la corrupción en el sector privado bajo el argumento de que los pactos internacionales no pueden sobreponer la soberanía estatal. Sumase a eso el hecho de que dicho tratado internacional es carente en mecanismos de seguimiento del cumplimiento de las disposiciones ratificadas y de mecanismos sancionatorios para los incumplimientos de los compromisos asumidos (Argandoña 2005, 10).

Muchos Estados-miembro de la Unión Europea castigan como delito el hecho de corrupción practicado en el sector privado con un tipo penal específico según los moldes de la Acción Común del bloco europeo, tales como Alemania (sección 299 y ss., Strafgesetzbuch); Austria (sección 305 y 306, Strafgesetzbuch); Francia (artículo 445-1 y ss., Code Pénal Français); Holanda (artículo 328ter, Dutch Criminal Code), y Reino Unido (sección 1 y 2, Bribery Act). Sin embargo, otros países europeos aún caminan demasiado lento en este aspecto, tal como Portugal e Italia, que sólo recientemente han criminalizado la corrupción en el sector privado, pero España es el peor ejemplo en este aspecto, pues aún no contempla en su legislación penal el castigo a la corrupción en el sector privado (De la Cuesta Arzamendi y Blanco Cordero 2002, 268). 
Mientras los países europeos tengan avanzado en lo que se refiere a la criminalización de la corrupción en el sector privado, debido sobre todo a las iniciativas de la Unión Europea, este avance no pertenece solamente a este continente, sino que países alienígenas al bloco europeo también han combatido la corrupción en el sector privado a través de la tipificación penal de la conducta. En el Oriente Medio, la corrupción en el sector privado es criminalizada en los Emiratos Árabes Unidos (artículo 236/ 1 del Código Penal) y Líbano (artículo 354 del Código Penal Libanes de 1943). En Asia, la corrupción en el sector privado es delito en Malasia (Malaysian Anti-Corruption Commission Act 2009) Singapur (Prevention of Corruption Act) y China (artículo 8.1, Anti-Unfair Competition Law; artículos 163, 164, 385, 387, 388, 389, 391, 392 y 393 del Código Penal Chino). En el Extremo Oriente, la corrupción en el sector privado es criminalizada en Ucrania (Law on Prevention of Corruption, Law on Fundamentals of Preventing and Combating Corruption y Criminal Code), Eslovenia (artículo 241 KZ-1 y 242 KZ-1 del Código Penal), Eslovaquia (artículo 328, 332, 336A y 336B, Código Penal), República Checa (secciones 331-334, Código Penal) y Bosnia y Herzegovina (Código Penal).

Sin embargo, aunque la corrupción en el sector privado haga sido contemplada por las legislaciones de los países europeos en virtud de las iniciativas comunitarias y en otros países del globo debido a los mandados de criminalización constantes en los tratados internacionales, resultado del consenso multilateral en los organismos internacionales, todos estos esfuerzos no han tenido un impacto sustantivo en las legislaciones de los países del continente americano, pues el derecho continental interamericano aún insiste en comprender la corrupción cómo el intercambio de una acción u omisión ejercido de manera irregular en el marco de una entidad de naturaleza pública objetivando una ventaja indebida (Encinar del Pozo 2016, 84).

El contexto de retraso relativo a las iniciativas normativas de combate a la corrupción en el sector privado es muy significativo en el continente americano, pues es la región con menor desarrollo en el mundo en lo que se refiere a esta materia. Tal retraso se reafirma cuando analizase las relaciones internacionales entre los Estados americanos dentro de la Organización de los Estados Americanos (OEA), cuyo instrumento internacional dedicado al combate a la corrupción es la Convención Interamericana Contra la Corrupción de 1997.

Esta obra está bajo una Licencia Creative Commons

Atribución-NoComercial-SinDerivar 4.0 Internacional, IIJ-UNAM.

Boletín Mexicano de Derecho Comparado, núm. 158, mayo-agosto de 2020, pp. 685-732. 
Contrariamente a las iniciativas del bloco europeo, que históricamente ha avanzado significativamente en el combate a la corrupción en el sector privado por medio de la criminalización del hecho delictivo entre particulares en las legislaciones de los Estados-miembros de la Unión Europea en virtud de los tratados comunitarios de fuerza imperativa, los países del continente americano viven un retroceso en este aspecto.

Así como en la Convención de Mérida, la Convención Interamericana es compuesta de normas de aplicación imperativa y las de carácter programático, significando un marco en la lucha contra la corrupción en la región interamericana, pero en lo que se refiere al combate a la corrupción en el sector privado el instrumento es deficitario, pues su alcance es limitado a la corrupción en el sector público y ni siquiera contempla disposición sobre la responsabilidad de las personas jurídicas, ni que sea civil o administrativa, demandando una actualización después de once años sin cualquier discusión.

Mientras el continente americano sea más permisivo con la corrupción en el sector privado que otros continentes, países como Perú y Colombia incorporaron en sus legislaciones la criminalización de la conducta. En Perú, se ha incorporado en el Código Penal, por medio del Decreto Legislativo 1385, los artículos 241-A y 241-B que prohíben las figuras de la corrupción en el ámbito privado y la corrupción en el interior de los entes privados. En Colombia, se adoptó, entre otras medidas contra la corrupción, la incorporación de los artículos 250A, 250B y 258 al Código Penal, mediante la Ley 1474/2011, que castigan las figuras de la corrupción privada, la administración desleal y la utilización indebida de información privilegiada.

Es importante destacar que el ordenamiento jurídico mexicano ha sido lo que más ha profundizado reformas legislativas de lucha contra la corrupción que no resultan ser resumidas a la creación de tipos penales, sino que ha sido una profunda reforma del diseño institucional encargado de combatir la corrupción en carácter preventivo, dirigente, combativo y sancionador. La reforma constitucional de 2015 estableció la creación del Sistema Nacional Anticorrupción (SNA), sustentado en el artículo 113 da la Constitución Política de los Estados Unidos Mexicanos, como la instancia de coordinación del agrupamiento de instituciones y autoridades de todos los órdenes de gobierno competentes en un mismo comité que, de forma alineada, persigue el objetivo de ejecutar la política nacional an- 
ticorrupción, sea a través de medidas de prevención, detección e sanción de responsabilidades administrativas y hechos de corrupción, como de fiscalización y control de recursos públicos.

En lo que se refiere a las modificaciones legislativa operadas en el seno del SNA mexicano, el paquete de leyes anticorrupción básicamente orientase en generar mecanismos de fiscalización y rendición de cuentas en todos los órdenes de gobierno del país y en cambiar el marco legal, notablemente el Código Penal Mexicano y la Ley de Fiscalía General de la República.

La Ley General del Sistema Nacional Anticorrupción establece las bases de coordinación del SNA, a nivel federal y local, así como las características del Sistema Nacional de Fiscalización y de la Plataforma Digital Nacional, además de planear las normas generales de funcionamiento del sistema y de que manera se hará la colaboración entre las instituciones vinculadas. La Ley General de Responsabilidades Administrativas, a ser observada por las leyes de los Estados, establece las obligaciones que todos los servidores públicos, detalla las responsabilidades administrativas y especifica a los tipos de corrupción que los oficiales y los particulares que de algún modo estén vinculados a las faltas administrativas no puedan practicar, así como establece los procedimientos de investigación, detección y sanción. La reforma de la Ley Orgánica del Tribunal Federal de Justicia Administrativa encargó al Tribunal la atribución de juzgar los posibles actos de corrupción que investiguen las autoridades y las faltas administrativas graves y crea al Tribunal Federal de Justicia Fiscal y Administrativa con autonomía para emitir sus fallos y con jurisdicción plena. Las reformas a la Ley Orgánica de la Administración Pública Federal establecieran la Secretaría de la Función Pública como órgano de gobierno encargado del control interno de la Administración Pública Federal, de investigación de responsabilidades administrativas graves y resolver las faltas administrativas no graves. Las reformas hechas a la Ley de Fiscalización y Rendición de Cuentas de la Federación dotaron la Auditoría Superior de la Federación de mayores facultades y herramientas de investigación para fiscalizar los recursos federales, incluso las participaciones estatales. Con las reformas de la Ley Orgánica e la Procuraduría General de la República se ha retornado con la Fiscalía Especializada de Combate a la Corrupción encargada de investigar y perseguir actos de corrupción. 
Sin embargo, a pesar del diseño institucional generado en el SNA constituirse en un modelo para otros países, con resultados claros en el combate a la corrupción, este desarrollo en el marco legal mexicano, por más vasto que sea, no ha contemplado la lucha contra la corrupción en el sector privado. No se puede confundir la sanción de empresas y particulares por actos de corrupción vinculados con los servidores públicos con los actos de corrupción puramente privados. La Ley General de Responsabilidades Administrativas prevé, entre los artículos 65 al 73, sanciones a empresas y particulares por actos vinculados con faltas administrativas graves que son marcadas por la involucración de agentes públicos, lo que no deja de ser actos de corrupción pública, ya que la participación del particular no desnaturaliza el carácter público de la corrupción, sino que es parte de ella. Al revés es la presencia del agente público lo que diferencia la corrupción pública de la privada, pues esta última caracterizase por el cohecho sólo entre particulares, sin la participación de un agente público.

La experiencia mexicana resulta demonstrar que la corrupción en el sector privado no está en la agenda de lucha contra la corrupción, así como lo suena ser en otros países de Latinoamérica.

En los EE. UU., mientras la legislación federal no posee un tipo penal que prohíba expresamente la conducta de corrupción entre particulares, el Departamento de Justicia, equivalente a la Fiscalía, se valle de una inteligencia jurídica de las normas para punir los hechos delictivos con base en conductas tipificadas como fraude, conspiración o lavado de dinero. Ante tal ausencia, los dispositivos legales relativos al fraude por correo, medio electrónico y de servicios honestos (S.18 § 1341, 1343, 1346, U.S. Criminal Law) y la Ley de Viajes son utilizados por el Departamento de Justicia para enjuiciar el soborno en el sector privado caso estos se vallan del uso de correo o de instalaciones de cable interestatal o cuando hay comunicaciones interestatales con el fin de violar las leyes estatales de soborno comercial. Sin embargo, las sanciones aplicables a dichos hechos con base en estos tipos delictivos son más brandas que el tipo penal de soborno previsto en la legislación estadounidense, pues tales tipos son pensados para situaciones menos complejas o cuya lesión al bien jurídico tutelado es de menor relevancia.

Mientras las legislaciones en el ámbito federal estadounidense tengan un papel inexpresivo en la lucha contra la corrupción en el sector privado, las legislaciones de 36 estados norteamericanos criminalizan la 
corrupción en el sector privado, entre los cuales California (sección 641.3, California Penal Code), Delaware (sección 881, Delaware Code), Massachusetts (sección 39, Massachusetts General Laws), New Jersey (sección 2C:21-10, The New Fersey Code of Criminal Justice) y Texas (sección 32.43, Texas Penal Code).

\section{EL PANORAMA LEGISLATIVO BRASILEÑO SOBRE LA CORRUPCIÓN EN EL SECTOR PRIVADO}

Brasil no distanciase tanto de la realidad estadounidense al que se refiere a la ausencia de legislación a nivel federal que castigue la corrupción en el sector privado, sin embargo, el panorama brasileño es aún peor porque no hay siquiera leyes estaduales, como en el contexto norteamericano, mismo que haya permisivo constitucional previsto en el párrafo único del artículo 22 de la Constitución de la República.

Así como el Departamento de Justicia de los EE. UU., la Fiscalía de Brasil no deja que la ausencia de un tipo penal específico que castigue los hechos de corrupción en el sector privado impida la persecución penal de las conductas para que sus agentes no permanezcan impunes, y eso ocurre a través de la aplicación de otros tipos penales que puedan ser adoptables. Sin embargo, la consecuencia es la misma verificada en el ejemplo norteamericano, que es la condenación con penas más brandas para hechos muy lesivos a bienes jurídicos muy caros, especialmente en el actual escenario de corrupción sistémica. Además, hay otro efecto negativo ante a esta carencia, que es la imposibilidad de cooperación penal internacional con otros países que estén investigando delitos de corrupción privada practicados por brasileños o mismo por extranjeros, pues en virtud de la atipicidad de la conducta la extradición o el cumplimiento de sentencia tornase imposible de acuerdo con las reglas constitucionales e infra constitucionales de naturaleza procesal penal.

Brasil asumió el compromiso internacional de acoger las disposiciones de la Convención de Mérida en 2003, con su entrada en vigor en el ordenamiento jurídico interno en 2006 por medio del Decreto 5.687, del 31 de enero de 2006. Sin embargo, hasta hoy, las medidas contra la corrupción en el sector privado no pasan de proyectos legislativos suspensos en los archivos del parlamento brasileño, pues en lo que se refiere a la criminali- 
zación de la corrupción en el sector privado, dicho tratado internacional produce tan sólo una recomendación.

Actualmente, los únicos instrumentos punitivos de hechos de corrupción en el sector privado vigente en Brasil son la Ley 12.529/2011, cuya finalidad es la prevención y represión a las infracciones contra el orden económico, y la Ley 9.279/1996, que reglamenta la propiedad industrial y prevé catorce tipos penales relacionados a la competencia desleal, pero que permanece sin eficacia practica en la represión a los delitos.

Tramita en el Senado Federal, desde el 2012, el Proyecto de Ley 236, para la institución de un nuevo código penal brasileño que propone en el capítulo de los delitos contra el patrimonio el artículo 167 que tipifica la figura del cohecho entre particulares. En un análisis comparado con el artículo 21 de la Convención de Mérida, el citado dispositivo de dicho proyecto de ley es positivo en lo que se refiere a los actos que componen la conducta típica, pues allá de los actos de prometer, ofrecer, conceder, solicitar y aceptar de la convención, la propuesta legislativa acrecienta la exigencia, recibimiento, pago y aceptar promesa, como hechos punibles. Sin embargo, la propuesta cumple deficitariamente la Convención, es decir, no adopta el texto mínimo acordado, pues a lo que se refiere al hecho activo inserto en el párrafo único del dispositivo propuesto, se pune sólo aquél que dirige el acto ilícito al representante de la entidad del sector privado y deja impune aquellos que objetivan practicar el delito frente a otros que ejercen cualquier actividad en la misma entidad.

Es importante señalar que, en dicho proyecto normativo, la tipificación de la corrupción entre particulares prevé una pena de prisión durante un periodo de uno a cuatro años, al paso que el cohecho contra la administración pública prevista en el artículo 276 conmina una pena de prisión de tres a ocho años. La menor severidad en el castigo a la corrupción cometida en el sector privado es injustificable y puede generar una idea de menor reprobación y consecuentemente un estímulo a tal conducta ya que la legislación aún permite la aplicación de sanciones alternativas a la prisión del agente debido al quantum de la pena máxima.

Otro equivoco de dicho proyecto de ley que puede explicar parte de tal discrepancia es la mala vinculación del delito a una lesión al patrimonio, al revés de asociarlo a una lesión contra el orden económico-financiero, que es un bien jurídico de mayor protección y, por lo tanto, las lesiones 
son más reprobables y resultarían en penas mayores, así como son los delitos contra la administración pública.

Una escandalosa trama de corrupción de repercusión mundial involucrando la Confederación Brasileña de Futbol (CBF), el Comité Organizador Local de la Copa del Mundo FIFA Brasil 2014 (COL) y la Federación Internacional del Futbol (FIFA), en actos de pago de soborno para cesión de derechos de trasmisión de los juegos de futbol de la Copa del Mundo de 2014, irregularidades en contractos diseñados para realización de partidas del time de futbol brasileño y de los juegos organizados por la $\mathrm{CBF}$, de la Copa de las Confederaciones FIFA 2013 y de la Copa del Mundo de 2014, impactó negativamente la percepción de la corrupción en Brasil (Bruno 2018).

Dicho escándalo no sólo desveló una trama sistémica y antigua de corrupción involucrando sujetos privados, cómo también señaló para el mundo que dichos hechos no podrían ser perseguidos por las autoridades brasileñas, pues la corrupción en este sector específico no estaba inserta en la legislación nacional como crimen. Esto se tornó aún más claro y vergonzoso cuando la autoridad judicial estadounidense condenó el ex presidente de la CBF, José Maria Marin, a pena de cuatro años de prisión cumulada con multa de $\$ 1,2$ millones por los delitos de crimen organizado, fraude bancario y lavado de dinero, al paso que en el territorio brasileño los delitos permanecieron impunes (Estern District of New York Attorney's Office 2018).

Otra trama de corrupción en el sector privado en Brasil se tornó un escándalo internacional en 2016, involucrando el ex jefe del Comité Olímpico Brasileño (COB), Carlos Arthur Nuzman, en pago de soborno de US $\$ 2$ millones para garantizar el voto del ex presidente de la Asociación Internacional de Federaciones Atléticas (IAAF), Lamine Diack, para elegir Rio de Janeiro como sede de los juegos olímpicos de 2016, mismo la ciudad poseyendo las peores condiciones para recibir el evento deportivo, desmembrándose para otros fraudes en el seno de los proyectos de construcción de la ciudad olímpica y compras de resultados de juegos (Fonseca 2016).

En virtud de los perenes escándalos de corrupción estrictamente perpetrada entre particulares con poder económico en el seno de las tramas deportivas de 2014 y 2016 en Brasil, fue propuesto el Proyecto de Ley 455, de 2016, por La Comisión Parlamentar de Investigación del Futbol, 
instalada en 2015 en el Senado Federal, para apurar posibles irregularidades en la realización de la Copa de las Confederaciones y de la Copa del Mundo de 2014. Dicho Proyecto de Ley visa acrecer en el actual Código Penal el artículo 196-A para tipificar como delito la conducta de corrupción privada, con sanción de prisión de uno a cuatro años.

La crítica que se hace a la redacción del tipo penal del Proyecto de Ley 455/2016 es que él limita los agentes a un rol taxativo, olvidando del tercero que comete las mismas conductas con la misma finalidad, razón por la cual, el texto del tipo penal del Proyecto de Ley 236/2012 es mejor diseñado, pues alcanza también al tercero, en sintonía con el texto propositivo de la Convención de Mérida, evitándose que se opere la impunidad de determinados sujetos, todavía, dicho dispositivo luego tornase inútil ante la apertura del texto sobre el hecho activo de la conducta a interpretaciones más restrictivas al campo de agentes del delito.

\begin{tabular}{|c|c|}
\hline $\begin{array}{c}\text { Instrumento } \\
\text { normativo }\end{array}$ & \multicolumn{1}{c|}{ Texto normativo } \\
\hline \multirow{1}{*}{$\begin{array}{c}\text { Artículo 21. Soborno en el sector privado } \\
\text { Cada Estado Parte considerará la posibilidad de adoptar las } \\
\text { medidas legislativas y de otra índole que sean necesarias para } \\
\text { tipificar como delito, cuando se cometan intencionalmente en el } \\
\text { curso de actividades económicas, financieras o comerciales: } \\
\text { a) } \\
\text { La promesa, el ofrecimiento o la concesión, en forma di- } \\
\text { recta o indirecta, a una persona que dirija una entidad } \\
\text { del sector privado o cumpla cualquier función en ella, de } \\
\text { un beneficio indebido que redunde en su propio prove- } \\
\text { cho o en el de otra persona, con el fin de que, faltando al } \\
\text { deber inherente a sus funciones, actúe o se abstenga de } \\
\text { actuar; } \\
\text { La solicitud o aceptación, en forma directa o indirecta, } \\
\text { por una persona que dirija una entidad del sector priva- } \\
\text { do o cumpla cualquier función en ella, de un beneficio in- } \\
\text { debido que redunde en su propio provecho o en el de otra } \\
\text { persona, con el fin de que, faltando al deber inherente a } \\
\text { sus funciones, actúe o se abstenga de actuar. }\end{array}$} \\
\hline
\end{tabular}




\begin{tabular}{|c|l|}
\hline \multirow{2}{*}{$\begin{array}{c}\text { PL 236, } \\
2012\end{array}$} & $\begin{array}{l}\text { Artículo 167. Exigir, solicitar, aceptar o recibir ventaja indebida, } \\
\text { como representante de la empresa o institución privada, para } \\
\text { favorecer a si o a tercero, directa o indirectamente, o aceptar } \\
\text { promesa de ventaja indebida, a fin de realizar u omitir acto } \\
\text { inherente a sus atribuciones. } \\
\text { Pena - prisión, de un a cuatro años. } \\
\text { Párrafo único. En las mismas penas incurre quien ofrece, promete, } \\
\text { entrega o paga, directa o indirectamente, al representante de la } \\
\text { empresa o institución privada, ventaja indebida. }\end{array}$ \\
\hline PL 455, & $\begin{array}{l}\text { Artículo 196-A. Exigir, solicitar, aceptar o recibir ventaja indebida, } \\
\text { el director, el administrador, el miembro del consejo o de órgano } \\
\text { técnico, el auditor, el gerente, el prepuesto, el representante o el } \\
\text { empleado de la empresa o institución privada, para favorecer a } \\
\text { si o a terceros, directa o indirectamente, o aceptar promesa de } \\
\text { ventaja indebida, a fin de realizar u omitir acto inherente a sus } \\
\text { atribuciones. } \\
\text { Pena - reclusión, de un a cuatro años, y multa- } \\
\text { Párrafo único. En las mismas penas incurre quien ofrece, promete, } \\
\text { entrega o paga, directa o indirectamente, la ventaja indebida. }\end{array}$ \\
\hline
\end{tabular}

Hace más de quince años después de la firma de la Convención de Mérida por parte del Estado brasileño que la criminalización de la corrupción entre particulares aún es una materia en "discusión" que tramita en los cajones del parlamento nacional brasileño, es decir, el lapso temporal entre la firma del tratado internacional y su ratificación a través de los tramites internos se extiende demasiado, mientras que un numero significativo de países ya adoptó la recomendación de tipificación de la corrupción privada desde la asunción del compromiso.

A pesar del tratado internacional posee mandados de criminalización de carácter imperativo y de normas de orden facultativa, la firma solemne del jefe de Estado no se ha comprendido por la academia como una simple formalidad accesoria en el proceso de conclusión de un tratado internacional, sino que un acto que genera un compromiso con el contenido integral del diploma, exceptuadas las reservas, y que parte del presupuesto de la obligación de buena fe de los Estados signatarios previsto en el artículo 18 de la Convención de Viena, de 1969, sobre el derecho de los tratados (Dinh, Daillier y Pellet 2003, 138-140). 
Dicho dispositivo de la mencionada Convención determina que los Estados que firman un tratado deben abstenerse de practicar cualquier acto que resulte en la frustración del objeto y de la finalidad del diploma. Para eso, aún que dicho tratado no esté en vigor, es decir, aún que no exista como una norma jurídica, la firma del Estado a un tratado internacional le genera la obligación de no hacer que consiste en abstenerse a cualquier acto que contraria el espirito del tratado.

En este contexto, parece correcta y asertiva la concepción de que así como los Estados cuando se comprometen con los mandatos de criminalización de un convenio internacional por medio de su firma, y más aún después de su ratificación, asumen una auto limitación al legislador ordinario en la elección de los bienes jurídicos penales, es decir, se comprometen a criminalizar determinados hechos considerados ofensivos a estos bienes jurídicos determinados mediante la imposición de sanción, también asumen un deber ante las normas recomendatorias de criminalización de al menos vincular el parlamento a la discusión legislativa sobre la protección de los bienes jurídicos a que se recomienda proteger, como un acto coherente con la búsqueda de realización del objeto y de la finalidad del tratado que se traduce en por lo menos hacer esfuerzos para cumplir integralmente el convenio internacional.

La existencia de normas facultativas en tratados internacionales que solamente recomiendan medidas de enfrentamiento a hechos ofensivos a determinados bienes jurídicos, tal como el artículo 21 de la Convención de Mérida, no son meros dispositivos figurativos sometidos a la soberanía absoluta y desmedida de lo Estados, pero también los vinculan en la medida que, a pesar de no estar obligados a tipificar los hechos, deben al menos considerarlos y eso implica en tomar iniciativas para discutir en el parlamento las recomendaciones hechas en los tratados internacionales ratificados en tiempo razonable, como un acto de buena fe esculpido en el artículo 18 del Convenio de Viena.

Así, solamente se puede decir que el Estado considera la posibilidad de adoptar la tipificación de la corrupción en el sector privado se este discute en el ámbito domestico según los tramites internos legislativos a respecto del tema que se materializa en los proyectos de ley de discusión parlamentar y en tiempo razonable. Sin embargo, lo que se critica en el escenario brasileño es que tal discusión es demasiado lenta, sin cualquier esfuerzo de los parlamentares de conferir la relevancia que el tema merece 
frente a los crecientes escándalos de corrupción, incluso en el sector privado, que han surgido en los últimos años.

Inicialmente, es fundamental establecer la premisa teórica de que es un gran error la idea de que la corrupción en el sector privado es menos peor o que causa menos efectos negativos sobre la sociedad. El predominio de los estudios acerca de la corrupción en el sector público sobre los del sector privado crea una falsa sensación de que el primer es más importante, pero, al revés, la prevalencia de estudios sobre la corrupción en el sector público puede ser explicada por la mayor dificultad de percepción de la corrupción en las relaciones entre particulares que, por su naturaleza, son privadas del conocimiento público y, por eso, hay pocos subsidios para la investigación.

Sin embargo, esto escenario ha cambiado gradualmente en los últimos años debido a la génesis de una serie de nuevos estudios a respecto de la corrupción en el sector privado, mucho impulsado por los movimientos de legislatura anticorrupción en diversos ordenamientos jurídicos por el mundo.

Especialmente en la última década, la teoría de los costes transaccionales ha contribuido demasiado para el aumento del interés científico sobre la corrupción privada y sobre su dicotómica relación con el sector público, siendo responsable por una serie de nuevos estudios que desvelaron al mundo un nuevo diseño paradigmático sobre el modus operandi de la corrupción y sus consecuencias.

Los primados de la teoría de los costes transaccionales apuntan para la existencia de diferentes tipos de incertidumbres presentes en el ambiente donde una organización actúa y que influyen en diferentes tipos de costes que, al final y al cabo, determinan la toma de decisiones de los entes privados (Karjalanen y Moxham 2013, 271). En lo que dice respecto a la corrupción, este estudio centrase en dos géneros de incertidumbres: la incertidumbre ambiental y la incertidumbre comportamental.

La incertidumbre ambiental consiste en la ambigüedad presente en el ambiente operacional relativa a la política, procedimientos y prácticas del gobierno que rige el territorio donde la organización está instalada, y a depender del grado de esa ambigüedad hay un menor o mayor grado de imprevisibilidad para los gestores (Miller 1992, 313). Con el objetivo de suprimir la incertidumbre ambiental, en general, los gestores buscan informaciones sobre el ambiente externo; sin embargo, cuando la capacidad 
de los gestores en esta búsqueda, que dígase de pasaje, es limitada, la previsión de los resultados de sus decisiones tornase más oscuro, culminando en el tipo de incertidumbre ambiental llamado de incertidumbre informacional (Grewatsch y Kleidienst 2017, 293).

Para hacer frente al aumento de la incertidumbre ambiental agravada por el riesgo de conocimiento sobre el ambiente externo, las organizaciones precipitan costes asociados a la búsqueda de informaciones necesarias para la ejecución de transacciones en el mercado de actuación, motivando las empresas a buscaren mercados menos inciertos en términos ambientales para disminuir los costes de información (Madhok 1996, 579).

Mientras la corrupción privada se opere en el seno de las relaciones privadas, el sector público no alejase por completo de mantener cierta influencia en este campo. Como se ha puesto de manifiesto en líneas anteriores, la política, procedimientos y prácticas del gobierno pueden significar una incertidumbre ambiental en la medida que sean poco transparentes o contradictorias. El gobierno brasileño transmite un ejemplo práctico de dicha proposición teórica en la medida que el jefe de Estado asume el compromiso de combatir la corrupción, incluso de discutir acciones efectivas de lucha contra el fenómeno en el sector privado, sin embargo, el Poder Legislativo se mantiene ineficiente en crear normas que tipifiquen tal conducta como delito, mismo frente a los recientes escándalos de corrupción involucrando el sector privado en dos eventos de alcance mundial - Copa del Mundo 2014 y Juegos Olímpicos 2016-, en un camino contrario al adoptado en relación a la corrupción en el sector público.

La postura del gobierno brasileño crea una imprevisibilidad para los gestores de organizaciones privadas que desean operar en el mercado nacional, que necesitan anticipar costes para colectar y procesar informaciones sobre la integridad ética de la iniciativa privada y sobre la inclinación política estatal en criminalizar la corrupción privada, así como lo hace con la pública.

El otro genero de incertidumbre es la comportamental que está asociada a la previsión de cual comportamiento ha de ser adoptado por las otras personas y cuanto más alta la tasa de incertidumbre más alto es el riesgo de oportunismo Brouthers y Brouthers 2003, 1187). El oportunismo es conceptualizado como el comportamiento de aprovechar la oportunidad para defraudar o engañar a otra parte de una relación (Smith 2018, 613). En el ambiente empresarial el oportunismo es una preocupación 
constante de los gestores en la conducción de los negocios que, de modo a prevenirse contra sus efectos, precipitan costes de monitoreo y ejecución, tanto para garantizar que las partes cumplan con sus obligaciones predeterminadas, como para castigar o ejercer control sobre la parte que incumpla sus obligaciones, respectivamente (Sampath, Gardberg y Rahman 2018, 745).

Las organizaciones, especialmente las transnacionales, buscan evitar altos costes de transacción relativos a la incertidumbre comportamental en determinados mercados, es decir, el objetivo es evitar mercados que exigen altos costes con monitoreo y seguimiento que consecuentemente impactan en los resultados de los negocios. En este sentido, la corrupción en el sector privado posee un impacto muy negativo sobre la fiabilidad de un mercado, pues le torna menos atrayente a inversiones de capital extranjero y estimula la fuga de capital nacional para otros mercados más fiables.

En el caso brasileño, la ocurrencia de los dos mencionados escándalos de corrupción involucrando los dos mayores eventos deportivos mundiales demuestra las debilidades del gobierno en hacer frente contra tales conductas, pues no sólo desvela la costumbre delictuosa, como también la carencia de instrumentos de persecución, que se agrava debido a la falta de interés del gobierno en luchar contra dicha práctica y tornar el mercado más seguro y atractivo para los negocios.

Engañase aquél que piensa que el país no sufre los perjuicios por la corrupción entre los particulares, así como los sufre la sociedad cuando se trata de desvío de dinero público. Los daños son colectivos, pues la economía nacional siente, como un todo, los impactos de un ambiente de incertidumbre comportamental, pues aumentase los costes de monitoreo y ejecución para hacer negocios en el país y consecuentemente, cuando de la toma de decisión de los gestores, le torna un destino menos atractivo en comparación con mercados más seguros en términos de posee instrumentos de represión contra la corrupción en el sector privado.

Los estudios científicos sobre las perversas consecuencias de la corrupción en el sector privado sobre la sociedad no es una exclusividad de las investigaciones jurídicas, habiendo por cierto una extensa gama de estudio en las áreas de administración y de la ciencia política (Montiel, Husted y Christimann 2012, 1107). Ninguna organización actúa aisladamente, pero si, hace parte de un sistema complejo, de un organismo inteligente 
conectado con tantas otras instituciones que no solamente entes privados. Dentro de esta organicidad están comprendidos varios actores del campo privado, tales como clientes, proveedores, inversionistas y empleados, los cuales componen lo que la ciencia de la administración y de economía llama de cadena de valor (Jung y Lee 2017, 686).

El éxito de una cadena de valor es sopesado por el grado de confianza entre los actores privados que la componen de que las transacciones serán ejecutadas según lo acordado y con que se espera de una relación íntegra. Sin embargo, la corrupción en el sector privado degrada los lazos de confianza necesario para el establecimiento y manutención de una cadena de valor exitosa, pues debilita la previsibilidad acerca de patrones de comportamiento esperados en las relaciones comerciales (Lange 2008, 717).

La desconfianza generalizada en virtud de un alto grado de percepción pública de corrupción en el sector privado, sobre todo en relación con la incertidumbre comportamental y el consecuente riesgo de oportunismo, hace con que haya un fuerte desestímulo en la realización de negocios en un determinado mercado, pues involucro altos costes de transacción, especialmente con mecanismos de monitoreo y de ejecución (Rose-Ackerman 2010, 222). Con el advenimiento de nuevas leyes nacionales de represión a la corrupción en el sector privado con alcance extraterritorial como la UK Bribery Act, por ejemplo, los costes de transacción para un negocio se firmar en un país marcado por la impunidad, como es el caso de Brasil, son muy altos y en muchos casos puede tornar la inversión desventajosa.

Así, la economía brasileña siente los efectos negativos de la ineficiencia legislativa en criminalizar la corrupción en el sector privado y del gobierno ejecutivo de desarrollar mecanismos más efectivos de control y represión a la corrupción entre particulares. Las empresas brasileñas también sufren el impacto negativo, tanto para hacer negocios internos frente a la desconfianza con los otros actores del mercado, como también para ampliar sus negocios para otros mercados ya que ellos son verdaderas banderas rojas para los empresarios extranjeros en la hora de considerar un acuerdo comercial.

Otro aspecto que carece ser debatido es el examen de la normativa brasileña dentro de un campo más largo que su análisis comparado en relación al sistema interamericano, pues, a diferencia de la Unión Europea, no hubo ningún esfuerzo por parte de la OEA para armonizar la 
legislación penal de los Estados miembros respecto al delito de corrupción en el sector privado, eso porque ni siquiera se dio el primer paso hacia un tratado con mandato imperativo de criminalización de la corrupción entre particulares.

Este esfuerzo hacia la armonización de las legislaciones penales de los países europeos se debe a un conflicto de normas con distintos modelos de tipificación del delito que pone en riesgo la efectividad de la cooperación internacional para cohibir su práctica, especialmente en los delitos de dimensión transnacional. Determinados ordenamientos jurídicos europeos tratan del delito de corrupción privada en el seno de las relaciones laborales como una desviación de los deberes de lealtad, confianza y buena fe por parte del empleado/agente frente al empleador/principal, como por ejemplo los artículos 445-1 y 445-2 del Código Penal Francés, el artículo 504bis del Código Penal Belga y el artículo 328 del Código Penal de los Países Bajos. Esta construcción legislativa tiene como objetivo frenar la conducta injusta del empleado que de mala fe abusa de la confianza del empleador para obtener ventajas indebidas, violando las reglas que rigen la relación laboral (Prado y Rossetto 2015, 55).

En algunos ordenamientos jurídicos europeos e incluso latinoamericanos el bien jurídico que se ha buscado proteger con la criminalización de la corrupción en el sector privado ha sido la competencia leal entre los sujetos particulares en el seno de las relaciones comerciales, evidenciando un contexto marcado por obligaciones de los operadores económicos hacia el mercado, como por ejemplo el artículo 286bis del Código Penal Español y la sección 10 del Código Penal Austríaco, el artículo 241-A del Código Penal Peruano y en los artículos 287bis y 287ter del Código Penal Chileno. En ese sentido, el bien jurídico protegido asume un carácter supraindividual de modo que el delito de corrupción privada es practicado cuando el cohecho entre particulares perjudica a los suministros de mercancías o prestaciones de servicios por otros operadores económicos bajo el régimen de competencia mercadológica, resultando irrelevante para la configuración del ilícito el consentimiento del empleador hacia los empleados en el seno de una relación laboral como en los tipos penales basados en la violación de deberes (Martín 2002, 57).

La criminalización de la corrupción en el sector privado en algunos ordenamientos jurídicos tutela el patrimonio de los socios e inversores, teniendo un contenido material respecto al bien jurídico protegido más 
concreto que en las variaciones ya mencionadas. En efectos prácticos, eso permite al aplicador de la norma penal delimitar con mayor seguridad la conducta delictuosa, vulnerando menos a los particulares con respecto al riesgo de interpretaciones casuísticas en perjuicio de los derechos individuales. En este modelo de incriminación es posible distinguir la falta de valor de la conducta fundada en el engaño y del resultado que es la lesión o exposición a un peligro real de lesión al patrimonio, como lo es el antiguo artículo 2635 del Código Civil Italiano y el artículo 251-A del Código Penal Colombiano (Prado y Rossetto 2015, 60).

Y la corrupción en el sector privado puede ser tipificada dentro de un diseño unitario que comprende en un solo tipo penal la corrupción tanto en el sector público como en el privado, también llamado por la doctrina jurídica comparada como delito de privatización administrativa, pero es mayoritariamente conocido como delito omnicomprensivo de la corrupción privada, tal como verificase en la sección 5 del capítulo 10 del Código Penal Sueco (Gontijo 2015, 33).

La discusión sobre los pros y contras de cada modelo de tipificación de la corrupción en el sector privado es tema para otro artículo más dedicado a la profundización de sus complejidades. Si bien Brasil discute proyectos de ley sobre la clasificación de la corrupción privada en línea con el texto mínimo de la Convención de Mérida con base en la violación de deberes, y en este sentido es consistente con el compromiso asumido, esta clasificación es criticada por la doctrina, pues al tratar el ilícito cómo una ruptura de la confianza en el seno de la relación laboral retira la legitimidad del Estado respecto a la iniciativa del enjuiciamiento de la acción penal, pues la desvaloración de la conducta depende de si el empleador considera que se han violado los deberes de lealtad por el empleado. Otro aspecto negativo de esta tipificación para la lucha contra la corrupción entre particulares es la complicidad del empleador con la conducta fraudulenta o su negligencia respecto a la ausencia de códigos de ética que establezcan deberes de buena fe e integridad, pues cualquier una de estas hipótesis torna la corrupción privada una conducta atípica. En otras palabras, no ha crimen se el empleador es el beneficiario de la actividad corrupta llevada a cabo por su empleado, pues este modelo tipificación supone que el sujeto corrupto únicamente pueda ser el empleado y no el empleador (Nieto 2002, 58). 
Es un consenso en la doctrina jurídica que este modelo de tipificación penal no cumple la finalidad de combatir la corrupción privada debido a la injustificada redoma de inimputabilidad de otros sujetos privados involucrados cómo el empleador, que en muchos casos es el líder de la conspiración y a quien pertenece la legitimidad para iniciar la acción penal, vaciando la propia eficacia de la norma penal, lo que es lo mismo que no tener la ley.

La corrupción es un fenómeno complejo y su tratamiento académico es muy reciente, especialmente en su aspecto privado, comparado a otras ramas del estudio de las ciencias sociales y humanas. Debido a esa característica, ha mucho que avanzar en las investigaciones sobre la corrupción entre particulares, sobre todo en el marco jurídico penal, siendo el actual panorama legal un marco inicial en constante evolución hacia una construcción más solida como la del cohecho, pero entre todas las alternativas de tipificación del delito, la que mejor cumple el intento de combatirlo es el modelo que lo concibe como un delito de infracción de la competencia leal.

Sin embargo, tal como los modelos anteriores, la tipificación de la corrupción privada enfocada en la infracción de la competencia leal no es exenta de críticas. En realidad, parte de la doctrina jurídica entiende que esta forma de regulación por hora es la que mejor cumple la finalidad de luchar contra la corrupción en el sector privado, pero su relevancia como bien jurídico para justificar la intervención penal es cuestionable, sosteniéndose que existen mecanismos extrapenales más directos y eficaces para proteger la lealtad competitiva que el derecho penal.

\section{CONCLUSIÓN}

En términos prácticos, el Estado brasileño no posee esfuerzos sustantivos para criminalizar la corrupción en el sector privado como lo hace con relación al sector público, en un claro conflicto de interés de los parlamentares y de los ciudadanos.

Infelizmente, los escándalos de corrupción involucrando agentes públicos, especialmente los relativos a la Operación Lava Jato, han ocupado el debate público, mucho por fuerza de la prensa, ofuscando el debate sobre la corrupción entre particulares. 
Este contexto contribuye para que los parlamentares desvíen la atención para otras medidas de combate al crimen bajo la escusa de una supuesta orden de importancia en donde la corrupción priva está entre los temas de última relevancia. Eso se percibe en el actual escenario de discusión parlamentar sobre el tema de la corrupción en que el Congreso Nacional brasileño se concentra en el proyecto legislativo sobre abuso de autoridad (PL 7596/2017) y el conjunto de proyectos legislativos anticrimen (PL 881/2019, PL 882/2019 y PL 38/2019) propuesto por el ministro de la Justicia Sergio Moro, que en nada contemplan el sector privado.

La carencia de medidas efectivas de los organismos internacionales para incentivar países como Brasil a implementar respuestas normativas contra la corrupción privada contribuye para la permanencia de estos panoramas de ineficiencia.

Mientras Brasil aun discute hace muchos años la criminalización de la corrupción entre particulares en coherencia con el texto mínimo de la Convención de Mérida, señalando que aún no hay ningún avance sustantivo, este modelo de tipificación es basado en la infracción de deberes, lo que es muy criticado por la academia frente a su fracaso en países que así lo adoptaron y después cambiaron sus legislaciones. No más indicado es que entre todos los modelos de tipificación de la corrupción existentes, el mejor modelo sería el basado en una infracción de la competencia leal que no es objeto de ninguna discusión por los parlamentares brasileños.

La historia brasileña ha mostrado que ni siquiera los escándalos de corrupción divulgados por la prensa que involucraron los dos mayores eventos deportivos sedeados en el país en la última década fueron capaces de surtir efecto sobre el comportamiento parlamentar de inclinación a la criminalización de la corrupción en el sector privado, diferentemente de lo que ocurre cuando el tema es la corrupción en el sector público.

Entre los muchos motivos posibles, hay la poca importancia que se confiere por la opinión pública, que solamente empieza a cambiar a partir del esfuerzo de concientización de las instituciones públicas, de las entidades de la sociedad civil y de los organismos internacionales. Eso camino es un proceso lento de "hormiga" que va produciendo efectos en un largo espacio de tiempo que requiere mucha paciencia y la asunción del riesgo de más perjuicios al orden económico del Estado.

Otra medida importante para presión a los Estados omisos es la actuación de los organismos regulatorios en imponer patrones de conducta 
éticas a las empresas del sector, como ya lo hace la Bolsa de Valores de São Paulo (Bovespa) con las imposiciones de niveles diferenciados de gobernanza corporativa para clasificar empresas de capital abierto en segmentos de mejor confiabilidad (nivel 1, nivel 2 y nuevo mercado). Se esto se repite en otros mercados regulados, tal práctica empieza a cambiar las costumbres comerciales y fortalecer una demanda por seguridad jurídica más sólida por medio de la edición de leyes de repercusión general, tal como la criminalización de conductas indeseadas socialmente.

Brasil curre el riesgo de tornarse un país menos atractivo a la inversión privada de empresas internacionales reguladas por legislaciones más efectivas en el combate a la corrupción con alcance extraterritorial. Así que los efectos de la omisión del Estado brasileño pueden ser sentidos en la economía en un futuro próximo, ante la posibilidad de Brasil figurar entre los países con mercados de mayor riesgo de desvíos éticos para los negocios internacionales.

Hay mucho que discutir sobre el tema del combate a la corrupción privada debido a su enfoque reciente y a la multiplicidad de soluciones posibles. Por eso, el debate no termina en las breves líneas de este estudio, pero si, es solamente un punto de partida para un espectro mayor de reflexión.

\section{REFERENGIAS}

ALAM, M. S. 1991. "Some economic cost of corruption in LDGs". Fournal of Development Studies (27), 89-97.

AIDT, T. S. 2003. "Economic analysis of corruption: a survey". Economic Fournal (113), 632-652.

Andvig, J. C., Fjeldstad, O. H., Weltzien, A., Amundsen, I., SisseNER, T. K., and SOREIDE, T. 2001. Corruption. A review of contemporary research. Bergen. Chr. Michelsen Institute.

Argandoña, A. 2003. "La corrupción en el sector privado". Documento de Investigación (531), 1-18.

ARGANDOÑA, A. 2005. "Private-to-private corruption". IESE Business School Working Paper (531), 1-20.

ARgandoña, A. y Berendson, R. M. 2009. "La lucha contra la corrupción: una perspectiva empresarial". Cuadernos de la Cátedra de Responsabilidad Social de La Empresa y Gobierno Corporativo (4), 8. 
Aristotle. 1905. Aristotle's Politics. Oxford. Clarendon Press.

BARDÓN, C. B. 2013. "El delito de corrupción privada: bien jurídico, estructura típica e intervinientes". Revista para el Análisis del Derecho (2), $2-10$.

BeATO, C., ZiLli, L. F. 2012. "A estruturação de atividades criminosas: um estudo de caso". Revista Brasileira de Ciências Sociais (80), 71-88.

BeCKeR, G. S. 1968. "Crime and punishment: an economic approach". Journal of Political Economy (81), 169-217.

BIASE, F. 2013. "Sistemas auto-organizadores físicos, biológicos, sociais e empresariais". International fournal of Knowledge Engineering and Management (2), 123-146.

Brouthers, K. D., Brouthers, L. E. 2003. "Why service and manufacturing entry mode choices differ: the influence of transaction cost factors, risk and trust". Fournal of Management Studies (5), 1179-1204.

BRunO, M. M. 2018. "How corruption and football are connected in Brazil". The Brazilian Report [sitio web], 13 de junio. https://brazilian.report/ society/2018/06/13/corruption-brazilian-football/.

BYRnE, D. S. 1998. Complexity theory and social sciences. Londres. Routledge.

CARnEGIE Endowement for International Peace. 2002. "Control de la corrupción: clave para el comercio orientado al desarrollo". Policy Outlook (4), $1-11$.

Cascón, F. G. 2012. "Corrupción en el sector privado (I): la corrupción privada y el derecho privado patrimonial". Fustitia (10), 281-342.

Castillo, G. B. 2005. "Principio de la legalidad y proceso penal". Derecho Penal y Criminología (78), 109-124.

Cuenca, Carlos G. C. 2009. La corrupción en la contratación pública en Europa. Salamanca, GL. Ratio Legis.

De la Cuesta ARZamendi, J. L. 2014. "La corrupción ante el derecho y la justicia". Diritto Penale Contemporaneo (1), 1-14.

De la Cuesta Arzamendi, J. L. y Blanco Cordero, I. 2002. "La criminalización de la corrupción en el sector privado: ¿Asignatura pendiente del derecho penal español?". La Ciencia del Derecho Penal Ante el Nuevo Siglo (1), 259-263.

Del Moral García, A. 2015. La justicia penal ante la corrupción. Catalunya: Generalitat de Catalunya.

Dinh, N. Q., Dailler, P., Pellet, A. 2003. Direito internacional público. 2 ed. Lisboa, PT. Fundação Calouste Gulbenkian. 
DotTi, R. A. 2015. "Principios fundamentales del Derecho penal brasileño". Bulletin de la société internationale de dénfense sociale pour une politique criminelle humaniste (30), 313-326.

ENCINAR DEL POZO, M. A. 2016. El delito de corrupción privada en el ámbito de los negocios. Navarra. Thomson Reuters-Aranzadi.

Estern District of New York Attorney's Office. 2018. "Former Brazilian soccer official sentenced to four years' imprisonment for racketeering and corruption offenses". United States' Department of Fustice [sitio web], 22 de agosto. https://wrww.justice.gov/usao-edny/pr/former-brazilian-soccerofficial-sentenced-four-years-imprisonment-racketeering-and.

FOLLONI, A. 2016. Introdução à teoria da complexidade. Curitiba. Jaruá Editora.

Fonseca, P. 2016. "Brazil Olympic chief brokered $\$ 2$ million bribe to buy Rio Games: police". Thomson Reuters [sitio web], 5 de septiembre. https://www.reuters.com/article/us-olympics-rio-corruption/brazil-olympicchief-brokered-2-million-bribe-to-buy-rio-games-police-idUSKCN1BG1HV.

FURTADO, L. R. 2012. As raízes da corrupção: estudos de casos e lições para o futuro. Tesis doctoral. Salamanca. Universidad de Salamanca.

GATHI, J. T. 2009. "Defining the relationship between human rights and corruption". University of Pennsylvania fournal of International Law (1), 125202.

GOMes, L. F. 2007. Direito penal: introdução e princípios fundamentais; volume 1. São Paulo. Editora Revista dos Tribunais.

Gontijo, C. A. G. 2015. "O crime de corrupção no setor privado: estudo de direito comparado e a necessidade de tipificação do delito no ordenamento jurídico brasileiro". Tesis doctoral. Universidade de São Paulo.

Grewatsch, S., Kleidienst, I. 2017. "When does it pay to be good? Moderators and mediators in the corporate sustainability - corporate financial performance relationship: a critical review". Fournal of Business Ethics (2), 383-416.

Gunther, M. 2011. Os axiomas de Zurique. Rio de Janeiro. Record.

Hershman, Michael J. 1996. "Métodos para la investigación de la corrupción”. Revista Chilena de Ciencia Política (18), 61-66.

HobBes, T. 1986. Leviathan. Baltimore. Penguin Books.

Huntington, S. P. 1968. Political order in changing societies. New Haven. Yale University Press.

Esta obra está bajo una Licencia Creative Commons

Atribución-NoComercial-SinDerivar 4.0 Internacional, IIJ-UNAM.

Boletín Mexicano de Derecho Comparado, núm. 158, mayo-agosto de 2020, pp. 685-732. 
Inglehart, R., Welzel, C. 2005. Modernization, Cultural Change, and Democracy: The Human Development Sequence. Cambridge. Cambridge University Press.

Jung, J. C., LEE, K. P. 2017. "Host country sourcing of multinational enterprises: a corporate social responsibility perspective". Fournal of Business Ethics (3), 683-701.

JURAEV, J. 2018. "Rational choice theory and demand for petty corruption". Fournal of Eastern European and Central Asian Research (5), 1-10.

Karjalainem, K., Moxham, C. 2013. "Focus on Fairtrade: propositions for integrating Fairtrade and supply chain management research". Fournal of Business Ethics (2), 267-282.

KenNy, G. 2006. "Measuring and reducing the impact of corruption in infrastructure". World Bank Policy Research Working Papers (4009), 1-42.

KHAN, M. H., and Jomo, K. S. 2000. Rents, rent-seeking and economic development. Cambridge. Cambridge University Press.

LANGE, D. 2008. "A multidimensional conceptualization of organizational corruption control". Academy of Management Review (3), 710-729.

LEFF, N. F. 1964. "Economic development through bureaucratic corruption". American behavioral scientist (3), 8-14.

LORENZ, E. 1972. Predictability: does de flap of a butterfly's wings in Brazil set off a tornado in Texas? Presentado en: American Association for the Advancement of Science en 29 de dicimebre. file:///Users/carlosgodoi/Downloads/5025-Texto\%20do\%20Artigo-18930-1-10-20171110.pdf.

Martínez, V. A., JuAnATey, O., BláZQUez, F. "Efectos de la corrupcón em la imagen percebida de las empresas". Revista de Estudios de Comunicación (17), 45-64.

MBAKU, J. M. 1992. "Bureaucratic corruption as rent seeking behavior". Konjunkturpolitic (38), 247-265.

MADHOK, A. 1996. "The organization of economic activity: transaction costs, firm capabilities, and the nature of governance". Organization Science (5), 577-590.

Machiavelli, N. 1981. The Prince. Harmondsworth, Eng. New York. Penguin Books.

MARTín, A. N. 2002. "La corrupción en el sector privado (reflexiones desde el ordenamiento español a la luz del Derecho comparado". Revista Penal (10), 55-69. 
Maging, B. C. 2010. Polybius’ Histories. New York. Oxford University Press.

MiLLER, K. D. 1992. "A framework for integrated risk management in international business". Fournal of International Business Studies (2), 311-331.

Montesquieu, G. S. 1823. The Spirit of Laws. London. J. Collingwood.

Montiel, I., Husted, B., Christiamann, P. 2012. "Using private management standard certification to reduce information asymmetries in corrupt environments". Strategic Management fournal (9), 1103-1113.

MotTA, F., Belém, B. 2018. "Persecution of the public interest in a scenario of multiple interests: the OCDE's recommendations and the conflicts regulated by Law 12.813/2013". Administrative Law Review (2), 149175.

Myrdal, G. 1997. Corruption as a hindrance to modernization in South Asia. En: Heidenheimer, A. J. Political corruption: a handbook. 4 ed. New Brunswick. Transaction Publishers.

Nieto, A. 2002. "La corrupción en el sector privado (reflexiones desde el ordenamiento español a la luz del Derecho comparado)". Revista Penal (10), 55-69.

NyE, J. N. 1967. "Corruption and political development: a cost-benefit analysis". The American Political Science Review (61), 417-427.

Olken, B. A., Pande, R. 2012. "Corruption in developing countries". Annual Review of Economics (4), 479-509.

OSTERFELD, D. Prosperity versus planning: how government stifles economic growth. Nueva York. Oxford University Press.

PRADO, L. R. y Rossetto, P. C. 2015. "Contributo ao estudo da corrupção delitiva entre particulares". Revista Brasileira de Ciências Criminais (114), 51-97.

Pérez Cepeda, A. I. y Bento SÁnchez, D. 2012. "La política criminal internacional contra la corrupción". I. B. Gómez de la Torre y A. E. Liberatore S. Bechara (coords). Estudios sobre la corrupción. Un reflexión hispano-brasileña. Salamanca, CL. Centro de Estudios Brasileños.

Robles, Manuela U. 2015. Corrupción, límites y psicoanálisis. Madrid. El Duende.

Rodríguez, R. C. 2008. "Derecho penal como ultima ratio. Hacia una política criminal racional". Revista Ius et Praxis (14), 13-48.

Rose-Ackerman, Susan. 1996. "The political economy of corruption: causes and consequences". Public Policy for the Private Sector (74), 1-4.

Esta obra está bajo una Licencia Creative Commons

Atribución-NoComercial-SinDerivar 4.0 Internacional, IIJ-UNAM.

Boletín Mexicano de Derecho Comparado, núm. 158, mayo-agosto de 2020, pp. 685-732. 
Rose-Ackerman, Susan. 2010. "The law and economics of bribery and extortion". Annual Review of Law and Social Science (6), 217-238.

Rose-Ackerman, S., PALIFKA, B. J. 1999. Corruption and government: causes, consequences and reform. Cambridge: Cambridge University Press.

Rose-Ackerman, Susan. 2002. "Corruption and the criminal law". Forum on Crime and Society (2), 3-21.

Rousseau, J. 1974. The Essential Rousseau: The Social Contract, Discourse on the Origin of Inequality, Discourse on the Arts and Sciences, The Creed of a Savoyard Priest. New York. New American Library.

Sampath, V. S., GardberG N. A., Rahman, N. 2018. "Corporate reputation's invisible hand: bribery, rational choice and market penalties". Fournal of Business Ethics (3), 743-760.

SATO, Eiiti. 2003. "Conflito e cooperação nas relações internacionais: as organizações internacionais no século XXI". Revista Brasileira de Política Internacional (2), 161-176.

Schünemann, Bernd. 1988. "Cuestiones básicas de dogmática jurídicopenal y de política criminal acerca de la criminalidad de empresa". Anuario de Derecho Penal y Ciencias Penales (41), 529-558.

Senturia, J. J. 1931. 1931. "Corruption, Political". Encyclopedia of the Social Sciences, vol. IV. New York: Crowell, Collier, Mcmillan.

SHEIFER, A., Vishny, R. W. 2003. "Corruption". Quarterly fournal of Economics (108), 599-617.

SMITH, J. 2018. "Efficiency and ethically responsible management". Fournal of Business Ethics (3), 603-618.

TANZI, V. 1998. "Corruption around the world". IMF Staff Papers (45), 559-594.

Tocqueville, A., Mansfield, H. C., and Winthrop, D. 2000. Democracy in America. Chicago. University of Chicago Press.

U.S. Department of Justice y U.S. Securities and Exchange Commission. 2012. A resource guide to the U.S. Foreign Corrupt Practices Act. Washington D.C. FGPA Unit.

VARGAS, Edmundo. 2004. "La lucha contra la corrupción en la agenda regional e internacional: las convenciones de la OEA y la ONU". Nueva Sociedad (194), 133-148. 